\title{
On the Drivers of Temperature Extremes on the Antarctic Peninsula During Austral Summer
}

\section{Sai Wang ( $\nabla$ wangs@cma.gov.cn )}

China Academy of Meteorological Sciences https://orcid.org/0000-0002-4648-0439

\section{Minghu Ding}

China Academy of Meteorological Sciences

Ge Liu

China Academy of Meteorological Sciences

\section{Ting Wei}

China Academy of Meteorological Sciences

\section{Wenqian Zhang}

China Academy of Meteorological Sciences

\section{Wen Chen}

Institute of Atmospheric Physics Chinese Academy of Sciences

\section{Tingfeng Dou}

University of the Chinese Academy of Sciences

\section{Cunde Xiao}

Beijing Normal University

\section{Research Article}

Keywords: temperature extremes, Antarctic Peninsula, temperature advection, Rossby wave trains

Posted Date: February 23rd, 2021

DOl: https://doi.org/10.21203/rs.3.rs-221785/v1

License: (c) (1) This work is licensed under a Creative Commons Attribution 4.0 International License.

Read Full License 

austral summer

$6 \quad{ }^{1}$ State Key Laboratory of Severe Weather and Institute of Tibetan Plateau \& Polar
Meteorology, Chinese Academy of Meteorological Sciences, Beijing 100081, China

${ }^{2}$ State Key Laboratory of Cryospheric Science, Northwest Institute of Eco-

Environment and Resources, Chinese Academy of Sciences, Lanzhou 730000, China

${ }^{3}$ Center for Monsoon System Research, Institute of Atmospheric Physics, Chinese Academy of Sciences, Beijing 100190, China

${ }^{4}$ College of Resources and Environment, University of Chinese Academy of Sciences, Beijing 100049, China

${ }^{5}$ State Key Laboratory of Earth Surface and Resource Ecology, Beijing Normal University, Beijing 100875, China

Submitted to Climate Dynamics

Submitted on February, 8, 2021 
Corresponding author*:

Prof. Minghu Ding,

State Key Laboratory of Severe Weather and Institute of Tibetan Plateau \& Polar Meteorology,

Chinese Academy of Meteorological Sciences, Beijing, China

Email: dingminghu@foxmail.com 

Abstract

On the basis of surface air temperature (SAT) observations from the Great Wall

Station located on the Antarctic Peninsula (AP) and ERA-Interim reanalysis data, the present manuscript investigates the role of atmospheric flow at intraseasonal and synoptic time scales in driving the temperature extremes over the AP during austral summer. Both warm and cold events can persist for multiple days and were maintained mainly by the advection of seasonal air temperature by intraseasonal winds. Synoptic winds can influence the temperature change around the peak time through their advection of seasonal temperature, thus determining the time of peak temperature anomalies. The generation of intraseasonal winds was closely associated with Rossby wave trains propagating along the polar front jet over the Atlantic sector of the Southern Ocean before the warm and cold events. The synoptic height anomalies before the warm events were also manifested as Rossby wave trains propagating along the polar front jet. However, synoptic Rossby wave trains were almost absent when the cold events occurred. Further analysis indicates that the weakened background flow during the cold events may have hindered the eastward travel of synoptic eddies. This study provides an important guidance for subseasonal to seasonal prediction on the AP.

Key words: temperature extremes, Antarctic Peninsula, temperature advection, Rossby wave trains 


\section{Introduction}

Variations in surface air temperature (SAT) may have pronounced impacts on glaciological, oceanographic, chemical and biological processes in the Antarctic and surrounding ocean areas (Scambos et al. 2000; Cook et al. 2005; Meredith and King 2005; Turner et al. 2017). As revealed by satellite images, the surface melting induced by an increase in SAT was the dominant process leading to the disintegration and collapse of ice shelves (Scambos et al. 2000; Fahnestock et al. 2002; Cook et al. 2005). Furthermore, the variations in SAT can impact the biological processes in the surrounding ocean areas. For example, the increase in SAT and resulting sea ice loss along the western Antarctic Peninsula (AP) have led to an increase in competition among krill-eating predators (Trivelpiece et al. 2011). Therefore, it is important to investigate the mechanisms that drive Antarctic SAT variability.

Because the western AP is one of the regions experiencing the most warming on the planet, the SAT variability over the western AP has recently gained increasing attention (Turner et al. 2005; Marshall et al. 2006; Turner et al. 2016; Jones et al. 2019). During the austral autumn, winter, and spring seasons, apparent warming signals have occurred over the western AP (King 1994; Turner et al. 2005; Ding and Steig 2013; Clem and Fogt 2015) related to tropical Pacific forcing during autumn. Autumn tropical Pacific forcing was suggested to deepen the Amundsen/Bellingshausen Sea low (ASL), which can reduce sea ice along the western AP coast and advect warmer air to the AP (Ding and Steig 2013). According to Li et al. (2014), wintertime sea surface warming related to the Atlantic Multidecadal Oscillation can also deepen the ASL, further 
contributing to the warming trend over the AP. During austral summer, a warming trend can be observed on the northeastern AP (Turner et al. 2005; Orr et al. 2008). Summertime warming can be partly attributed to the positive trend in the Southern Annular Mode (SAM) (Orr et al. 2004; Marshall et al. 2006), which is induced by stratospheric ozone depletion and increasing greenhouse gas concentrations (Thompson et al. 2002; Marshall and Gareth 2003; Arblaster and Meehl 2006; Thompson et al. 2011). Since the late 1990s, an apparent decrease in SAT on the AP has occurred, which is due to natural variability (Hawkins et al. 2016; Turner et al. 2016; Ding et al., 2020). The temperature over the AP is characterized by large interannual variability, especially over the western AP (Marshall et al. 2006; Clem and Fogt 2013). According to previous studies, the change in the phase of the SAM can exert the greatest control on the interannual variability in SAT across the AP (Marshall and Thompson 2016; Turner et al. 2020). When the SAM is its positive (negative) phase, an increase (decrease) in the temperature can be observed across the AP (Marshall and Thompson 2016). The variations in the phase of the El Niño-Southern Oscillation (ENSO) and the associated tropical Pacific-high latitude teleconnection can also influence winter temperatures on the AP (Marshall and King 1998; Clem et al. 2016; Clem et al. 2017). Furthermore, the magnitude of the teleconnection is modulated by the magnitude and phase of the SAM (Fogt et al. 2011). Significant teleconnections can be observed only when ENSO events occur with a weak SAM or when ENSO is in phase with the SAM. The aforementioned efforts have helped to improve our understanding of the mechanisms of climate variability on the AP from interannual to multidecadal time 
scales. However, there is still a general lack of investigation about the mechanisms of extreme temperature events on the AP. In fact, weather or climate extremes could have a large influence on the Antarctic cryosphere and ecosystems. Investigating the dynamic mechanisms governing extreme temperatures on the AP can improve our understanding of the climate variability on the AP. Furthermore, revealing the precursory signals of extreme temperatures on the AP can provide important guidance for the subseasonal prediction of the climate variability in the region, which is one aim of the Polar Prediction Project (Jung et al., 2016). The main goal of this study is to investigate the dynamic mechanisms governing summertime extreme warm and cold temperatures on the AP. The rest of the paper is organized as follows: the observational and reanalysis data and methods used in this study are introduced in Sect. 2. The results are presented in Sect. 3. Sect. 4 provides a summary.

\section{Data and methods}

The present study employs the SAT from the Great Wall Station $\left(62^{\circ} 13^{\prime} \mathrm{S}, 58^{\circ} 58^{\prime} \mathrm{W}\right.$; WMO ID: 89058), which is located on the Fildes Peninsula of King George Island. The daily SAT is obtained by calculating the average value of observations taken at six-hour intervals (0000, 0600, 1200 and 1800 UTC). This study also employs the daily horizontal wind, air temperature, geopotential height, vertical motion at different pressure levels, sea level pressure (SLP) and SAT data from the European Centre for Medium-Range Weather Forecasts (ECMWF) ERA-Interim reanalysis (Dee et al. 2011). The atmospheric data from ERA-Interim reanalysis have a horizontal resolution of $2.5^{\circ}$ 
$\times 2.5^{\circ}$ and are available for 1979 to 2018 .

Extreme warm (cold) events are identified as when the normalized SAT values at the Great Wall Station exceed $1(-1)$ standard deviation and persist for longer than or equal to 3 days. Since the present study mainly focuses on persistent warm and cold events, the threshold is selected as durations greater than or equal to 3 days. It should be noted that the obtained results do not change for other similar thresholds, such as 5 days. The day when the normalized SAT values reach the maximum is taken as a reference (lag 0 day). Composite analysis is performed to obtain the common features of the extreme events during the $1985 / 86$ to $2017 / 18$ summers. According to our definition of extreme temperature events, 42 warm events and 48 cold events are identified during the period of 1986-2018 (Tables 1, 2).

The present study extracts synoptic, intraseasonal and seasonal variations from the original field using Butterworth high-pass (shorter than 8 days), bandpass (8-90 days) and low-pass (longer than 90 days) filters. The weights of the Lanczos filters are 17 for synoptic variations and 181 for intraseasonal and seasonal variations. The storm track activity is represented by the root mean square of the 2-8 day bandpass filtered 300hPa meridional wind (Wang et al. 2020b; Wang et al. 2020c). In the present study, the temperature tendency equation is used to reveal the dynamic mechanisms driving the temperature anomalies. The temperature tendency equation is written as:

$$
\frac{\partial T}{\partial t}=-\vec{V} \cdot \nabla T+S_{P} \omega+Q,(1)
$$

where $\mathrm{T}$ is the temperature, $\vec{V}$ is the horizontal velocity, $s_{P}=-\frac{T}{\theta} \frac{\partial \theta}{\partial P}$ is the static stability for which $\theta$ is the potential temperature, and $\omega=\frac{d P}{d t}$ is the vertical motion. 
The first term on the right-hand side (r.h.s.) is the horizontal temperature advection; the second term accounts for the adiabatic heating contribution; $Q$ represents the remaining diabatic heating contribution. The horizontal temperature advection and adiabatic heating terms at the surface are calculated following the method of Lee et al. (2011). To evaluate the contribution of atmospheric flow at different time scales in driving the temperature anomalies, the advection term in the temperature tendency equation is decomposed following the method of Song et al. (2018): First, any variable such as $A$ can be decomposed as:

$$
A=A^{S}+A^{L}+A^{H}
$$

where the superscripts $\mathrm{S}, \mathrm{L}$ and $\mathrm{H}$ denote the seasonal, intraseasonal and synoptic components. Thus, the advection terms associated with the intraseasonal oscillations (ISOs), synoptic variations and mixture of the ISOs and synoptic variations can respectively be expressed as:

$$
\begin{gathered}
u^{L} \frac{\partial T^{L}}{\partial x}+u^{L} \frac{\partial T^{S}}{\partial x}+u^{S} \frac{\partial T^{L}}{\partial x}+v^{L} \frac{\partial T^{L}}{\partial y}+v^{L} \frac{\partial T^{S}}{\partial y}+v^{S} \frac{\partial T^{L}}{\partial y} \\
u^{H} \frac{\partial T^{H}}{\partial x}+u^{H} \frac{\partial T^{S}}{\partial x}+u^{S} \frac{\partial T^{H}}{\partial x}+v^{H} \frac{\partial T^{H}}{\partial y}+v^{H} \frac{\partial T^{S}}{\partial y}+v^{S} \frac{\partial T^{H}}{\partial y} \\
u^{L} \frac{\partial T^{H}}{\partial x}+u^{H} \frac{\partial T^{L}}{\partial x}+v^{L} \frac{\partial T^{H}}{\partial y}+v^{H} \frac{\partial T^{L}}{\partial y},(3)
\end{gathered}
$$

The present study also employs the wave activity flux proposed by Takaya and Nakamura (2001) to illustrate the propagation of atmospheric stationary Rossby waves. Two-tailed Student's $t$ test is used to evaluate the statistical significance of the composite analysis.

\section{Results}




\subsection{The evolution of SAT anomalies}

Figures 1 $\mathrm{a}$ and $\mathrm{b}$ display the evolution of the composite SAT anomalies at the Great Wall Station during the lag -10 to lag +10 days of warm and cold events, respectively. For the warm events, the temperature anomalies at the Great Wall Station were above $0{ }^{\circ} \mathrm{C}$ from day -10 to day +10 (Fig. 1a). However, the magnitudes of the temperature anomalies were relatively small from day -10 to day -4 and from day +4 to day +10 (Fig. 1a). After day -4 , the temperature anomalies increased rapidly and reached the peak value on lag 0 day (Fig. 1a). After the peak time (day 0 ), the temperature anomalies decayed rapidly from day 0 to day +4 and returned to small positive values on day +4 (Fig. 1a). For the cold events, anomalies with opposite signs are observed. During the periods of lag -10 to lag -4 days and lag +4 to lag +10 days, small negative values of SAT anomalies can be observed (Fig. 1b). During lag -4 to lag 0 days, the temperature anomalies declined rapidly and reached the lowest value on lag 0 day. The temperature anomalies recovered to small negative values during lag 0 to lag +4 days. By comparison, the magnitude of the peak temperature anomaly of the cold events (approximately $3{ }^{\circ} \mathrm{C}$ ) is larger than that of the warm events (less than $3{ }^{\circ} \mathrm{C}$ ).

Next, the spatiotemporal evolution of SAT anomalies for the warm and cold events is assessed. On day -4 of the warm events, weak but significant warm anomalies can be observed over the region of the Drake Passage (Fig. 2a). Then, both the spatial coverage and magnitude of the warming anomalies increased. On day -2 , the warm anomalies expanded southward to the AP region (Fig. 2b). Meanwhile, significant cold anomalies appeared over the Amundson Sea (Fig. 2b). From lag -2 to lag 0 days, both the warm 
and cold anomalies increased gradually and reached their peak values on day 0 (Figs. $2 b, c)$. On day +2 , the warm anomalies over the Drake Passage and the cold anomalies over the Amundson Sea weakened (Fig. 2d). On day -4 of cold events, significant cold anomalies covered the southern part of South America, the Drake Passage and the northern part of the AP (Fig. 2e). On day -2, the cold anomalies expanded southward to the whole peninsula and were sustained to day +2 (Figs. 2f-h). On day 0 , the cooling anomalies reached their peak values, and the maximum of the cold anomalies was located on the northern part of the AP (Fig. 2g), corresponding to the peak value of SAT anomalies at the Great Wall Station.

Next, the synoptic, intraseasonal, and seasonal components of the temperature anomalies at the Great Wall Station are extracted to quantitatively evaluate the contributions to the variations in temperature at different time scales. As displayed in Figure 3 , the contributions to temperature anomalies at different time scales varied in different periods. The seasonal temperature anomaly during the lifetime of the warm (cold) events maintained a stable value of approximately $0.48{ }^{\circ} \mathrm{C}\left(-0.56{ }^{\circ} \mathrm{C}\right)$, which made the largest contribution to the total temperature anomaly from day -10 to day -4 and from day +4 to day +10 (Fig. 3). During lag -3 to lag +3 days, the intraseasonal temperature anomaly accounted for the majority of the total temperature anomalies, indicating the importance of the ISOs to the occurrence and strength of the temperature events (Fig. 3). On the peak day, the magnitudes of the synoptic temperature anomalies were second only to those of the intraseasonal temperature anomalies (Fig. 3), indicating the important role of the synoptic temperature anomalies in influencing the 
peak time of temperature anomalies.

Figures 4 and 5 display the spatiotemporal evolutions of SAT anomalies induced by intraseasonal, synoptic and seasonal variations for the warm events and cold events, respectively. As shown in Figures 4a-d, the spatial pattern of the temperature anomalies due to the ISOs is very similar to that of the original anomalies from lag -4 to lag +2 days. Furthermore, their magnitude made the largest contribution to the original anomalies. For the synoptic temperature, significant warm anomalies over the Drake Passage can be observed only on day 0 (Fig. $4 \mathrm{~g}$ ). On day +2 , the warm anomalies associated with the synoptic variations over the Drake Passage were replaced by cold anomalies (Fig. 4h). For the seasonal component, stable warm anomalies can be observed over the Drake Passage (Figs. 4i-1), which implies that persistent warm events are likely to occur during a warmer summer. During lag -4 to lag +2 days, the magnitudes of synoptic and seasonal temperature anomalies over the Drake Passage were smaller than those of intraseasonal anomalies, which indicates the dominant contribution of ISOs to the total temperature anomalies. For the cold events, the spatial pattern of the ISO-induced temperature anomalies was also very similar to that of the original anomalies during the lifetime of the cold events (Fig. 5). Furthermore, seasonal temperature anomalies may provide favourable conditions for the occurrence of persistent cold events (Figs. 5i-1). The SAT anomalies induced by synoptic variations can only account for the cooling anomalies over the northern part of the AP on day 0 of the cold events (Fig. 5g). By comparison, the ISO-induced temperature anomalies made the dominant contribution to the total temperature anomalies during lag -4 to lag +2 
days of the cold events (Fig. 5).

\subsection{Diagnostic analysis of SAT anomalies}

According to the above analysis, the temporal evolutions of SAT anomalies of the extreme temperature events at the Great Wall Station are closely related to the development of SAT anomalies over the Drake Passage region $\left(70^{\circ} \mathrm{S}-50^{\circ} \mathrm{S}\right.$ and $80^{\circ} \mathrm{W}-$ $\left.50^{\circ} \mathrm{W}\right)$. To explore the influence of the anomalous atmospheric flow on the SAT anomalies, the contributions of the horizontal advection term and diabatic heating term are assessed first in this section. Figure 6 displays the composite anomalies of SAT and the tendency of the SAT anomalies averaged over the Drake Passage region during lag -5 to lag +5 days of the warm and cold events. The evolution of the composite SAT anomalies over the Drake Passage region based on the ERA-Interim data matches well with the observed SAT anomalies at the Great Wall Station. As shown in Figures 6a and $\mathrm{d}$, the regionally averaged temperature anomalies (black line) increase in magnitude from day -5 to day 0 and reach the peak value on lag 0 day. After the peak (day 0 ), the temperature anomalies decay from day 0 to day +5 (Figs. 6a, d). The tendency of the observed air temperature anomalies (red line) is positive from lag -5 to lag 0 days of the warm events (Fig. 6a), which corresponds well to the increase in the warm anomalies over the Drake Passage region. After day 0, the regionally averaged values of the temperature tendency become negative (Fig. 6a), which corresponds to the decay of the warm anomalies over the Drake Passage. For the cold events, the composite SAT tendency is negative overall before lag 0 day (Fig. 6d), corresponding to the 
enhancement of the cold anomalies over the Drake Passage region. After the peak day (day 0 ), the observed tendency of temperature turns positive, indicating the weakening of the cold anomalies (Fig. 6f). According to Figure 6b, the horizontal advection term facilitates the development of the warm anomalies during lag -4 to lag +4 days of the warm events. The diabatic heating term can only act to weakly impede the growth of the warm anomalies from lag -1 to lag +3 days (Fig. 6b). At the developing stage of the warm events (lag -4 to lag 0 days), the positive temperature tendency induced by the horizontal advection term is overall larger than the observed tendencies (Fig. 6b). This implies that the development and maintenance of the warm anomalies was mainly induced by the horizontal advection term, whereas the adiabatic heating term may have made the dominant contribution in impeding the growth of the warm anomalies. Similarly, the development and maintenance of the cold anomalies was also mainly induced by the horizontal advection term (Fig. 6e).

To shed light on the role of atmospheric flow at intraseasonal and synoptic time scales in inducing temperature anomalies, the temperature tendency induced by different parts of the advection term is further examined. In Figure 6c, the advection term associated with the ISOs evolves slowly and maintains a positive value larger than those of the other two terms from lag -5 to lag +4 days. This suggests the important role of the ISOs in sustaining the duration of the warm events. From day -2 to day +1 , the advection term associated with the synoptic variations was positive and made a nonnegligible contribution to the advection term on day 0 (Fig. 6c). This indicates that the synoptic variations are important to the temperature increase around the peak time. The 
ISOs also played an important role in sustaining the duration of temperature events (Fig. 6f). The advection term associated with the synoptic variations was negative from day -2 to day +1 (Fig. 6f), decreasing the temperature around the peak time of the cold events. During the lifetimes of both the warm and cold events, the tendencies induced by the mixed terms were small, indicating their limited contributions to the evolution of SAT.

Figure 7 shows different parts of the advection terms associated with the ISOs and synoptic variations on lag 0 days of the warm and cold events. After decomposing the advection term, it is found that the term $v^{L} \frac{\partial T^{S}}{\partial y}$ was the primary contributor to the positive anomalies of tendency on lag 0 day of the warm events, whereas the term $v^{H} \frac{\partial T^{S}}{\partial y}$ played a secondary role in inducing the positive anomalies of tendency (Figs. 7a, b). Therefore, the development of warm anomalies over the Drake Passage around the peak time was mainly induced by the meridional advection of seasonal air temperature by intraseasonal and synoptic meridional wind anomalies. For the cold events, the term $v^{L} \frac{\partial T^{S}}{\partial y}$ acted as the primary contributor to the maintenance of cold anomalies (Fig. 7c). In addition, the terms $u^{L} \frac{\partial T^{S}}{\partial x}$ and $v^{H} \frac{\partial T^{S}}{\partial y}$ also made nonnegligible contributions to the cooling tendency (Figs. 7c, d). In general, intraseasonal and synoptic wind anomalies are vital to the formation of temperature anomalies around the peak time of temperature events.

\subsection{The associated atmospheric circulation anomalies}

The above analysis indicates the important role of intraseasonal and synoptic wind 
anomalies in inducing temperature tendency anomalies. This section assesses the detailed evolution of atmospheric circulation anomalies. Figure 8 displays the composite anomalies of the intraseasonal components of SLP and surface horizontal wind during lag -4 to lag +2 days of the warm and cold events. On lag -4 day of the warm events, an anomalous cyclone can be observed west of the Drake Passage (Fig. 8a). The northerly (southerly) wind anomalies prevailed on the cyclone's east (west) side (Fig. 8a), facilitating the advection of warm (cold) air from low (high) latitudes and the formation of warm (cold) anomalies. On day -3 , an anomalous anticyclone formed east of the Drake Passage (Fig. 8b). The collocation of the anomalous cyclone west of the Drake Passage and the anticyclone east of the Drake Passage can lead to warm anomalies over the region of the Drake Passage. The SLP and wind anomalies due to the ISOs increased in their magnitudes gradually from lag -4 to 0 days (Figs. $8 \mathrm{a}$, c), which corresponds well to the increase in warm anomalies over the Drake Passage. On day +2 of the warm events, the anomalous cyclone west of the Drake Passage weakened (Fig. 8d), which can explain the decrease in the temperature tendency induced by ISOs. During lag -4 to lag +2 days of the cold events, the composite pattern of SLP anomalies due to the ISOs is characterized by an anomalous anticyclone over the Bellingshausen Sea and an anomalous cyclone east of the Drake Passage (Figs. 8eh). Under the influence of the dipole pattern, southeasterly wind anomalies prevailed over the region of the Drake Passage, which can lower the temperature through advection of the seasonal SAT. The magnitudes of ISO-induced SLP and southeasterly wind anomalies intensified from lag -4 to lag 0 days (Figs. 8e-g). As a result, the 
negative anomalies of the temperature tendency increased in magnitude, which is conducive to the development and maintenance of cooling anomalies over the region of the Drake Passage, including the AP. On day +2 , the weakening of the intraseasonal SLP and wind anomalies led to a decrease in the magnitudes of advection terms associated with the ISOs (Fig. 8h).

Figure 9 displays the composite anomalies of the synoptic component of SLP and surface horizontal wind during lag -2 to lag +1 days of the warm and cold events. Different from the SLP anomalies due to ISOs, apparent eastward propagation of synoptic SLP anomalies can be observed during the lifetime of the temperature events. On lag -2 day of the warm events, an anomalous cyclone appeared over the Amundson Sea (Fig. 9a). The anomalous cyclone moved to the Bellingshausen Sea on lag -1 day (Fig. 9b). Meanwhile, an anomalous anticyclone can be observed east of the anomalous cyclone (Fig. 9b). On the peak day of the warm events, the anomalous cyclone (anticyclone) moved into the region east (west) of the Drake Passage (Fig. 9c). Under the influence of the synoptic SLP pattern, warm air can be advected to the Drake Passage by the northerly wind anomalies, producing positive values of temperature anomalies. On day +1 , the collapse of the synoptic cyclone west of the Drake Passage and ongoing eastward movement of the synoptic anticyclone east of the Drake Passage destroyed the favourable conditions for the increase in synoptic temperature over the Drake Passage (Fig. 9d). For the cold events, apparent synoptic SLP anomalies can be observed only around the peak day of the cold events. On lag 0 day, a small-scale anomalous cyclone appeared over the Weddell Sea (Fig. 9g). The synoptic circulation 
pattern was conductive to the advection of cold air to the southern edge of the AP. However, no anomalous anticyclone appeared upstream or downstream of the anomalous cyclone.

Next, the spatiotemporal evolution of upper tropospheric $(300 \mathrm{hPa})$ circulation anomalies are assessed. Figure 10 displays the intraseasonal component of 300-hPa geopotential height anomalies and associated wave activity flux during lag -6 to lag 0 days of the warm and cold events. The composite pattern of the intraseasonal height anomalies for the warm and cold events are both manifested as a Rossby wave train propagating along the polar jet over the Atlantic Sector of the Southern Ocean. On lag -6 days of the warm events, an anticyclonic centre can be observed east of New Zealand (Fig. 10a). Due to the southeastward propagating stationary Rossby wave packet emanating from the anticyclonic centre east of New Zealand, cyclonic anomalies formed and developed over the Amundsen/Bellingshausen Sea (ABS) (Figs. 10a, b). The cyclonic anomalies over the ABS intensified and further triggered eastward propagating stationary Rossby waves, leading to the formation of anticyclonic anomalies east of the Drake Passage on day -2 (Fig. 10c). On the peak day of the warm events, the action centres east of the Drake Passage gradually amplified with continuous eastward propagation of wave activity fluxes (Fig. 10d). However, the magnitude of the anticyclonic centre east of New Zealand weakened on day 0 (Fig. 10d). On day -6 of the cold events, an intraseasonal wave train can be observed, with anticyclonic centres over New Zealand and cyclonic centres over the region east of New Zealand (Fig. 10e). Due to the ongoing eastward propagation of wave activity fluxes emanating from New 
Zealand, anticyclonic anomalies over the Bellingshausen Sea and cyclonic anomalies east of the Drake Passage formed and intensified (Figs. 10e-h). On day 0, the magnitude of the cyclonic anomalies east of the Drake Passage reached its peak values (Fig. 10h), which correspond well with the peak values of SAT over the Drake Passage. However, the magnitude of the upstream geopotential height anomalies weakened, as did the associated wave activity fluxes (Fig. 10h).

Figure 11 displays the synoptic component of 300 -hPa geopotential height anomalies and associated wave activity flux for the warm and cold events. During the lifetime of the warm events, the composite pattern of synoptic height anomalies displayed a wave train pattern along the band within $50^{\circ} \mathrm{S}-60^{\circ} \mathrm{S}$ (Figs. 11a-d). Unlike intraseasonal Rossby waves, synoptic Rossby waves are characterized by short wavelengths and fast propagation speeds, which can explain the large mobility of surface circulation and temperature anomalies on the synoptic time scale. However, no apparent synoptic Rossby wave train can be observed from day -2 to day +1 of the cold events (Figs. 11e-h). A natural question is why synoptic Rossby waves were absent during the lifetime of the cold events. Previous studies have indicated that synoptic eddies are steered by upper-level winds (Wallace et al. 1988; Chang and Yu 1999; Wang et al. 2020a; Wang et al. 2021). The weaker zonal wind may hinder the eastward propagation of synoptic eddies from the region. Therefore, it is hypothesized that the absence of synoptic Rossby wave trains is due to weak background westerlies. The following evidence is presented to confirm the hypothesis. Figure 12 displays the composite anomalies of the seasonal component of 300-hPa zonal wind and storm track 
activity when the extreme cold events occurred. As the seasonal component of zonal wind and storm track activity did not vary much within a few days, we display only the seasonal component of zonal wind and storm track activity on day 0 of the cold events. As shown in Figure 12a, remarkable weakening of the 300-hPa zonal wind can be observed over the Drake Passage. Under the influence of the background flow, fewer synoptic eddies can propagate from the ABS to the Drake Passage, which is expressed as a decrease in the storm track activity along $60^{\circ} \mathrm{S}$ (Fig. 12b). The synoptic SLP and surface wind anomalies around the peak time of the cold events are probably induced by the local cyclone.

\section{Summary}

On the basis of observational SAT from the Great Wall Station, the present study identified 42 warm events and 48 cold events over the AP during the 1985/86 to 2017/18 summers. It was found that the temporal evolutions of SAT anomalies during the lifetimes of the warm and cold events were closely related to the development of SAT anomalies over the Drake Passage region. Further diagnostic analysis indicated that the development of the SAT anomalies over the Drake Passage region during the lifetimes of the warm and cold events was induced mainly by the horizontal advection term. Then, it was revealed that the advection terms induced by ISOs made the largest contribution to sustaining the temperature extremes. The advection terms associated with synoptic variations were found to make non-negligible contributions to the formation and development of temperature anomalies around the peak time of 
temperature events, indicating their important role in determining the time when the temperature anomalies peak.

As illustrated in Figure 13, the atmospheric flow at intraseasonal and synoptic time scales plays an important role in the formation of both the warm and cold events. The advection terms associated with ISOs and synoptic variations were mainly induced by the advection of seasonal air temperature by intraseasonal and synoptic winds. The prevailing intraseasonal northerly wind anomalies during the lifetime of the warm events were accompanied by anomalous cyclones west of the Drake Passage and anomalous anticyclones east of the Drake Passage, which were parts of the intraseasonal Rossby wave train propagating along the polar front jet over the Atlantic Sector of the Southern Ocean. Before the warm events, the intraseasonal Rossby wave packet emanating from the anticyclonic centre east of New Zealand led to the formation and development of cyclonic anomalies over the ABS and anticyclonic anomalies east of the Drake Passage. For the cold events, the positive SLP anomalies over the Bellingshausen Sea and negative anomalies east of the Drake Passage and associated southeasterly wind anomalies were also closely related to the intraseasonal wave train propagating along the polar front jet. The ongoing eastward propagation of wave activity fluxes emanating from anticyclonic centres over New Zealand was suggested to induce the formation and development of anticyclonic anomalies over the Bellingshausen Sea and cyclonic anomalies east of the Drake Passage.

The synoptic variations associated with the development of the warm events manifest as shorter and faster moving Rossby wave trains. In contrast, synoptic Rossby 
wave trains cannot be observed during the lifetime of the cold events. Further analysis indicated that the absence of the synoptic wave train was due to the weakened background flow. A decrease in the seasonal zonal wind can be observed over the Drake Passage when the cold events occurred, which may have hindered the eastward travel of synoptic eddies. The synoptic anomalies of SLP and surface wind were assumed to be induced by the local cyclone. Further analysis is needed to shed light on the role of short-term cyclones in influencing climate change on the AP.

\section{Acknowledgements:}

This research was funded by the National Science Foundation of China (41771064), the CN National Research and Development Projects, grant number 2019YFC1509100 and the Basic Research Fund of the Chinese Academy of Meteorological Sciences, grant number 2019Z008. This is a contribution to the Year of Polar Prediction (YOPP), a flagship activity of the Polar Prediction Project (PPP), initiated by the World Weather Research Programme (WWRP) of the World Meteorological Organization (WMO).

\section{Conflicts of interest:}

The authors declare no potential conflicts of interest. 


\section{Reference:}

Arblaster JM, Meehl GA (2006) Contributions of External Forcings to Southern Annular Mode Trends. Journal of Climate 19:2896-2905

Chang EKM, Yu DB (1999) Characteristics of Wave Packets in the Upper Troposphere. Part I: Northern Hemisphere Winter. Journal of the Atmospheric Sciences $42: 1708-1728$

Clem KR, Fogt RL (2013) Varying roles of ENSO and SAM on the Antarctic Peninsula climate in austral spring. Journal of Geophysical Research: Atmospheres 118:11,481-411,492. https://doi.org/10.1002/jgrd.50860

Clem KR, Fogt RL (2015) South Pacific circulation changes and their connection to the tropics and regional Antarctic warming in austral spring, 1979-2012. Journal of Geophysical Research: Atmospheres 120:2773-2792. https://doi.org/10.1002/2014jd022940

Clem KR, Renwick JA, Mcgregor J (2017) Large-Scale Forcing of the Amundsen Sea Low and Its Influence on Sea Ice and West Antarctic Temperature. Journal of Climate 30:8405-8424

Clem KR, Renwick JA, Mcgregor J, Fogt RL (2016) The relative influence of ENSO and SAM on Antarctic Peninsula climate. Journal of Geophysical Research: Atmospheres 121:9324-9341

Cook AJ, Fox AJ, Vaughan DG, Ferrigno JG (2005) Retreating glacier fronts on the Antarctic Peninsula over the past half-century. Science 308:541-544. https://doi.org/10.1126/science.1104235 
Dee DP et al. (2011) The ERA-Interim reanalysis: configuration and performance of the data assimilation system. Quarterly Journal of the Royal Meteorological Society 137:553-597. https://doi.org/10.1002/qi.828

Ding M, Han W, Zhang T, Yue X, Fyke J, Liu G, Xiao C (2020) Towards More Snow Days in Summer since 2001 at the Great Wall Station, Antarctic Peninsula: The Role of the Amundsen Sea Low. Advances in Atmospheric Sciences 37: 494-504.

Ding Q, Steig EJ (2013) Temperature Change on the Antarctic Peninsula Linked to the Tropical Pacific*. Journal of Climate 26:7570-7585. https://doi.org/10.1175/jcli-d-12-00729.1

Fahnestock MA, Abdalati W, Shuman CA (2002) Long melt seasons on ice shelves of the Antarctic Peninsula: an analysis using satellite-based microwave emission measurements. Annals of Glaciology, 34: 127-133. doi:10.3189/172756402781817798

Fogt RL, Bromwich DH, Hines KM (2011) Understanding the SAM influence on the South Pacific ENSO teleconnection. Climate Dynamics 36:1555-1576

Hawkins E, Smith RS, Gregory JM, Stainforth DA (2016) Irreducible uncertainty in near-term climate projections. Climate Dynamics 46:3807-3819. https://doi.org/10.1007/s00382-015-2806-8

Jones ME, Bromwich DH, Nicolas JP, Carrasco J, Plavcová E, Zou X, Wang S-H (2019) Sixty Years of Widespread Warming in the Southern Middle and High Latitudes (1957-2016). Journal of Climate 32:6875-6898. https://doi.org/10.1175/jcli-d$\underline{18-0565.1}$ 
Jung T, Gordon ND, Bauer P, Bromwich DH, Chevallier M, Day JJ, Dawson J., DoblasReyes F, Fairall C, Goessling HF, Holland M, Inoue J, Iversen T, Klebe S, Lemke P, Losch M, Makshtas A, Mills B, Nurmi P, Perovich D, Reid P, Renfrew IA, Smith G, Svensson G, Tolstykh M, Yang Q (2016) Advancing Polar Prediction Capabilities on Daily to Seasonal Time Scales. Bulletin of the American Meteorological Society 97: 1631-1647. doi: 10.1175/BAMS-D-1400246.1

King JC (1994) Recent climate variability in the vicinity of the antarctic peninsula. International Journal of Climatology 14:357-369. https://doi.org/10.1002/joc.3370140402

Lee S, Gong T, Johnson N, Feldstein SB, Pollard D (2011) On the Possible Link between Tropical Convection and the Northern Hemisphere Arctic Surface Air Temperature Change between 1958 and 2001. Journal of Climate 24:4350-4367

Li X, Holland DM, Gerber EP, Yoo C (2014) Impacts of the north and tropical Atlantic Ocean on the Antarctic Peninsula and sea ice. Nature 505: 38-542. https://doi.org/10.1038/nature12945

Marshall, Gareth J (2003) Trends in the Southern Annular Mode from observations and reanalyses. Journal of Climate 14:4134-4143

Marshall GJ, King JC (1998) Southern hemisphere circulation anomalies associated with extreme Antarctic peninsula winter temperatures. Geophysical Research Letters 25:2437-2440. https://doi.org/10.1029/98g101651

Marshall GJ, Orr A, van Lipzig NPM, King JC (2006) The Impact of a Changing 
Journal

of

Climate

19:5388-5404. https://doi.org/10.1175/jcli3844.1

Marshall GJ, Thompson DWJ (2016) The signatures of large-scale patterns of atmospheric variability in Antarctic surface temperatures. Journal of Geophysical Research-Atmospheres 121:3276-3289. https://doi.org/10.1002/2015jd024665

Meredith MP, King JC (2005) Rapid climate change in the ocean west of the Antarctic Peninsula during the second half of the 20th century. Geophysical Research Letters 32: L19604. https://doi.org/10.1029/2005g1024042

Orr A, Cresswell D, Marshall GJ, Hunt JCR, Sommeria J, Wang CG, Light M (2004) A 'low-level' explanation for the recent large warming trend over the western Antarctic Peninsula involving blocked winds and changes in zonal circulation. Geophysical Research

Letters

31: L06204. https://doi.org/10.1029/2003g1019160

Orr A et al. (2008) Characteristics of Summer Airflow over the Antarctic Peninsula in Response to Recent Strengthening of Westerly Circumpolar Winds. Journal of the Atmospheric Sciences 65:1396-1413. https://doi.org/10.1175/2007jas2498.1

Scambos TA, Hulbe C, Fahnestock M, Bohlander J (2000) The link between climate warming and break-up of ice shelves in the Antarctic Peninsula. Journal of Glaciology 46:516-530. https://doi.org/10.3189/172756500781833043 
Song L, Wu R, Jiao Y (2018) Relative contributions of synoptic and intraseasonal variations to strong cold events over eastern China. Climate Dynamics 50: 4619-4634. https://doi.org/10.1007/s00382-017-3894-4

Takaya K, Nakamura H (2001) A Formulation of a Phase-Independent Wave-Activity Flux for Stationary and Migratory Quasigeostrophic Eddies on a Zonally Varying Basic Flow. Journal of Atmospheric Sciences 58: 608-627

Thompson, David WJ, Solomon, Susan (2002) Interpretation of Recent Southern Hemisphere Climate Change. Science 296: 895-899

Thompson DWJ, Solomon S, Kushner PJ, England MH, Grise KM, Karoly DJ (2011) Signatures of the Antarctic ozone hole in Southern Hemisphere surface climate change. Nature Geoence 4:741-749

Trivelpiece WZ, Hinke JT, Miller AK, Reiss CS, Trivelpiece SG, Watters GM (2011) Variability in krill biomass links harvesting and climate warming to penguin population changes in Antarctica. Proceedings of the National Academy of Sciences of the United States of America 108:7625-7628. https://doi.org/10.1073/pnas.1016560108

Turner J et al. (2005) Antarctic climate change during the last 50 years. International Journal of Climatology 25:279-294. https://doi.org/10.1002/joc.1130

Turner $\mathrm{J}$ et al. (2016) Absence of 21st century warming on Antarctic Peninsula consistent with natural variability. Nature 535:411-415. https://doi.org/10.1038/nature18645

Turner J, Marshall GJ, Clem K, Colwell S, Phillips T, Lu H (2020) Antarctic 
temperature variability and change from station data. International Journal of Climatology 40:2986-3007. https://doi.org/10.1002/joc.6378

Turner J, Orr A, Gudmundsson GH, Jenkins A, Bingham RG, Hillenbrand C-D, Bracegirdle TJ (2017) Atmosphere-ocean-ice interactions in the Amundsen Sea Embayment, West Antarctica. Reviews of Geophysics 55:235-276. https://doi.org/10.1002/2016rg000532

Wallace JM, Lim G-H, Blackmon ML (1988) Relationship between Cyclone Tracks, Anticyclone Tracks and Baroclinic Waveguides. Journal of the Atmospheric Sciences $\quad 45: 439-462 . \quad$ https://doi.org/10.1175/1520-0469(1988)045<0439: Rbctat $>2.0 . \mathrm{Co} ; 2$

Wang S, Chen W, Chen S, Ding S (2020a) Interdecadal change in the North Atlantic storm track during boreal summer around the mid-2000s: role of the atmospheric internal processes. Climate Dynamics 55:1929-1944. https://doi.org/10.1007/s00382-020-05360-w

Wang S, Chen W, Chen S, Nath D, Wang L (2020b) Anomalous winter moisture transport associated with the recent surface warming over the Barents-Kara seas region since the mid-2000s. International Journal of Climatology 40:2497-2505. https://doi.org/10.1002/joc.6337

Wang S, Nath D, Chen W, Wang L (2020c) Changes in winter stationary wave activity during weak mid-latitude and Arctic thermal contrast period. International Journal of Climatology 40:1755-1768. https://doi.org/10.1002/joc.6299

Wang S, Nath D, Chen W (2021) Nonstationary relationship between sea ice over Kara- 
638

\begin{tabular}{llll}
\hline Year & Lag 0 day & Year & Lag 0 day \\
\hline $1985-1986$ & Feb 14 & $2002-2003$ & \\
$1986-1987$ & & $2003-2004$ & \\
$1987-1988$ & Feb 13; Feb 21 & $2004-2005$ & \\
$1988-1989$ & Dec 30; Feb 25 & $2005-2006$ & Jan 4; Jan 18; Feb 7 \\
$1989-1990$ & Dec 29; Jan 19; Feb 13; Feb & $2006-2007$ & Dec 4; Feb 11 \\
& 27 & & \\
$1990-1991$ & Jan 12 & $2007-2008$ & Feb 24 \\
$1991-1992$ & & $2008-2009$ & Dec 19 \\
$1992-1993$ & Dec 2; Dec 24; Feb 11 & $2009-2010$ & \\
$1993-1994$ & & $2010-2011$ & \\
$1994-1995$ & Dec 5; Dec 17; Jan 21; Jan & $2011-2012$ & \\
& 24; Feb 11 & & \\
$1995-1996$ & Feb 18 & $2012-2013$ & \\
$1996-1997$ & Dec 21; Jan 14; Jan 24; Feb & $2013-2014$ & \\
& 14 & & \\
$1997-1998$ & Jan 14 & $2014-2015$ & \\
$1998-1999$ & Feb 24 & $2015-2016$ & \\
$1999-2000$ & Dec 27 & $2016-2017$ & Dec 4; Feb 10 \\
$2000-2001$ & Feb 27 & $2017-2018$ & Dec 27; Feb 24 \\
$2001-2002$ & Dec 3; Dec 15; Jan 1 & & \\
\hline
\end{tabular}

639

640

641

642

643

644

645

646 

cold events.

650

\begin{tabular}{llll}
\hline Year & Lag 0 day & Year & Lag 0 day \\
\hline $1985-1986$ & Feb 18; Feb 28 & $2002-2003$ & Dec 4 \\
$1986-1987$ & Dec 8; Jan 10 & $2003-2004$ & Dec 6; Dec 18 \\
$1987-1988$ & & $2004-2005$ & Dec 16 \\
$1988-1989$ & Dec 2; Jan 23 & $2005-2006$ & Dec 7; Dec 20 \\
$1989-1990$ & & $2006-2007$ & Dec 24 \\
$1990-1991$ & Dec 2; Dec 14; Feb 22 & $2007-2008$ & \\
$1991-1992$ & Dec 7; Dec 18; Dec 25; Feb & $2008-2009$ & Feb 15 \\
& 14; Feb 28 & \\
$1992-1993$ & & $2009-2010$ & Dec 1; Jan 9; Jan 13; Jan \\
& & & $27 ;$ Feb 5; Feb 21 \\
$1993-1994$ & Feb 18 & $2010-2011$ & Dec 7; Jan 21 \\
$1994-1995$ & & $2011-2012$ & Feb 19 \\
$1995-1996$ & & $2012-2013$ & Dec 6; Jan 27 \\
$1996-1997$ & & $2013-2014$ & Jan 8; Feb 9 \\
$1997-1998$ & Dec 28 & $2014-2015$ & Feb 27 \\
$1998-1999$ & & $2015-2016$ & Jan 11; Jan 25; Feb 17 \\
$1999-2000$ & & $2016-2017$ & Feb 20 \\
$2000-2001$ & Jan 1; Feb 6; Feb 10; Feb & $2017-2018$ & \\
\hline & 18; Feb 23 & & \\
\hline
\end{tabular}

651 


\section{Figure Captions:}

Fig. 1 Time evolution of surface air temperature (SAT) anomalies $\left({ }^{\circ} \mathrm{C}\right)$ at the Great Wall Station during lag -10 to lag +10 days of (a) warm and (b) cold events.

Fig. 2 Composite SAT anomalies $\left({ }^{\circ} \mathrm{C}\right)$ on days (a) -4 , (b) -2 , (c) 0 and (d) +2 of the warm events. (e)-(h) are the same as (a)-(d) but for cold events. The dots indicate anomalies significant at the $95 \%$ confidence level. The green dot indicates the location of the Great Wall Station.

Fig. 3 The same as Fig. 1 but for the synoptic, intraseasonal, and seasonal components of SAT.

Fig. 4 Composite anomalies of the intraseasonal component of SAT $\left({ }^{\circ} \mathrm{C}\right)$ on days (a) 4, (b) -2 , (c) 0 and (d) +2 of the warm events. (e)-(h) and (i)-(l) are the same as (a)-(d) but for the synoptic and seasonal components of SAT, respectively. The dots indicate anomalies significant at the $95 \%$ confidence level. The green dot indicates the location of the Great Wall Station.

Fig. 5 The same as Fig. 4 but for the cold events.

Fig. 6 Time evolution of the composite anomalies of (a) SAT (black line), SAT tendency (red line), (b) SAT tendency induced by advection (red line) and adiabatic (black line) terms and (c) SAT tendency caused by different parts of the advection term averaged over the Drake Passage $\left(70^{\circ} \mathrm{S}-50^{\circ} \mathrm{S}\right.$ and $\left.80^{\circ} \mathrm{W}-50^{\circ} \mathrm{W}\right)$ during lag -5 to lag +5 days of the warm events. (d)-(f) are the same as (a)-(c) but for the cold events. Fig. 7 Different parts of advection terms associated with the (a), (c) ISOs and (b), (d) synoptic variations on lag 0 day of the warm and cold events, respectively. 
Fig. 8 Composite anomalies of intraseasonal components of SLP (hPa) (shading) and surface winds $\left(\mathrm{ms}^{-1}\right)$ (vectors) on days (a) -4 , (b) -2, (c) 0 and (d) +2 of the warm events. (e)-(h) are the same as (a)-(d) but for the cold events. The dots indicate anomalies significant at the $95 \%$ confidence level.

Fig. 9 Composite anomalies of synoptic components of SLP (hPa) (shading) and surface winds ( $\mathrm{ms}^{-1}$ ) (vectors) on days (a) -2 , (b) -1, (c) 0 and (d) +1 of the warm events. (e)-(h) are the same as (a)-(d) but for the cold events. The dots indicate anomalies significant at the $95 \%$ confidence level.

Fig. 10 Composite anomalies of the intraseasonal component of geopotential height anomalies at $300 \mathrm{hPa}(\mathrm{m})$ (shading) and the attendant wave activity flux (vector) on days (a) -6 , (b) -4 , (c) -2 and (d) 0 of the warm events. (e)-(h) are the same as (a)-(d) but for the cold events. The dots indicate anomalies significant at the $95 \%$ confidence level.

Fig. 11 Composite anomalies of the synoptic component of geopotential height anomalies at $300 \mathrm{hPa}(\mathrm{m})$ (shading) and the attendant wave activity flux (vector) on days (a) -2 , (b) -1 , (c) 0 and (d) +1 of the warm events. (e)-(h) are the same as (a)-(d) but for the cold events. The dots indicate anomalies significant at the $95 \%$ confidence level.

Fig. 12 Composite anomalies of the seasonal component of (a) 300-hPa zonal wind $\left(\mathrm{ms}^{-1}\right)$ and (b) 300-hPa storm track activity (m) for the cold events. The dots indicate anomalies significant at the $95 \%$ confidence level.

Fig. 13 Schematic illustration of the role of atmospheric flow in the formation 

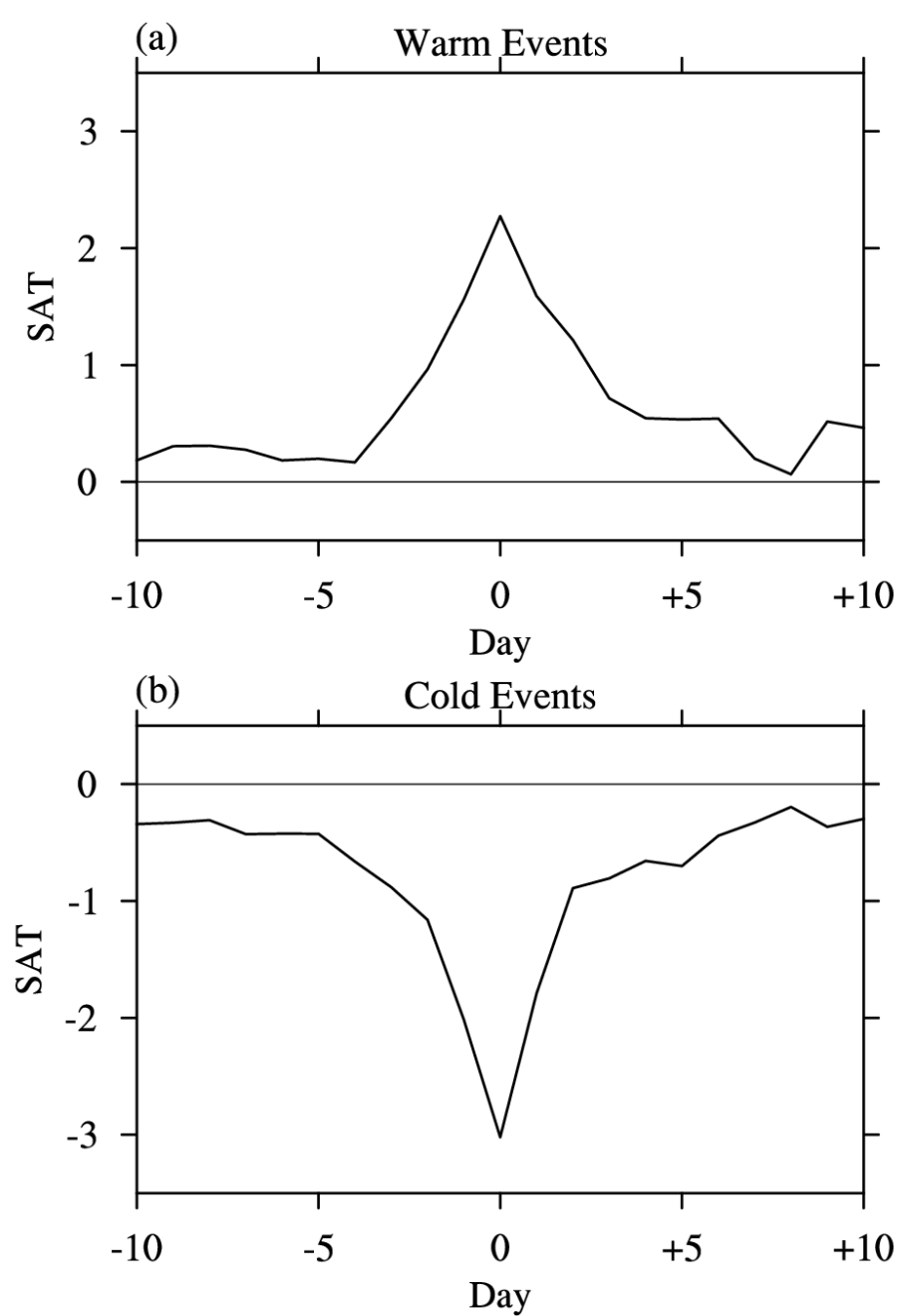

723 Fig. 1 Time evolution of surface air temperature (SAT) anomalies $\left({ }^{\circ} \mathrm{C}\right)$ at the Great 


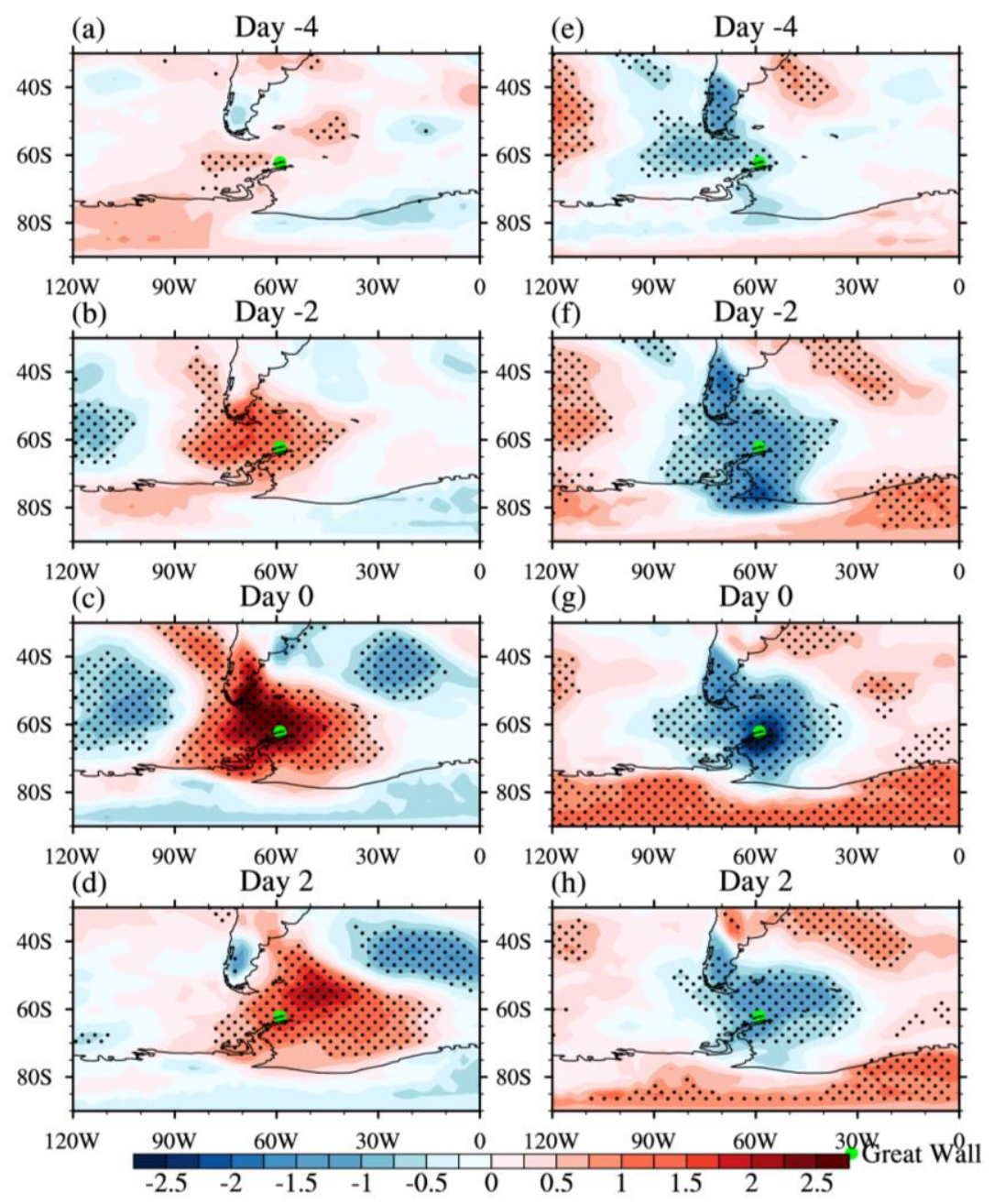

Fig. 2 Composite SAT anomalies $\left({ }^{\circ} \mathrm{C}\right)$ on days (a) -4 , (b) -2 , (c) 0 and (d) +2 of the warm events. (e)-(h) are the same as (a)-(d) but for cold events. The dots indicate anomalies significant at the $95 \%$ confidence level. The green dot indicates the 


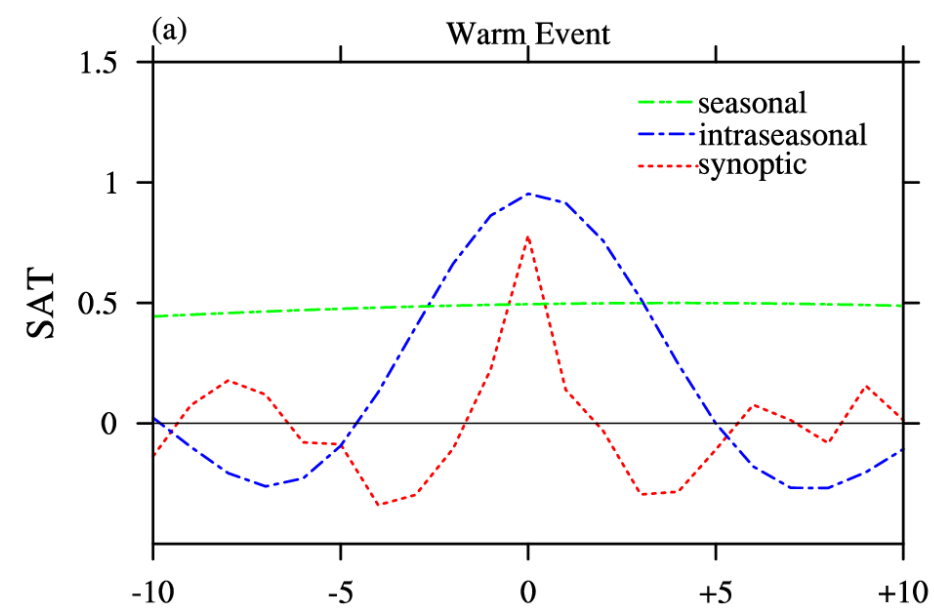

Day

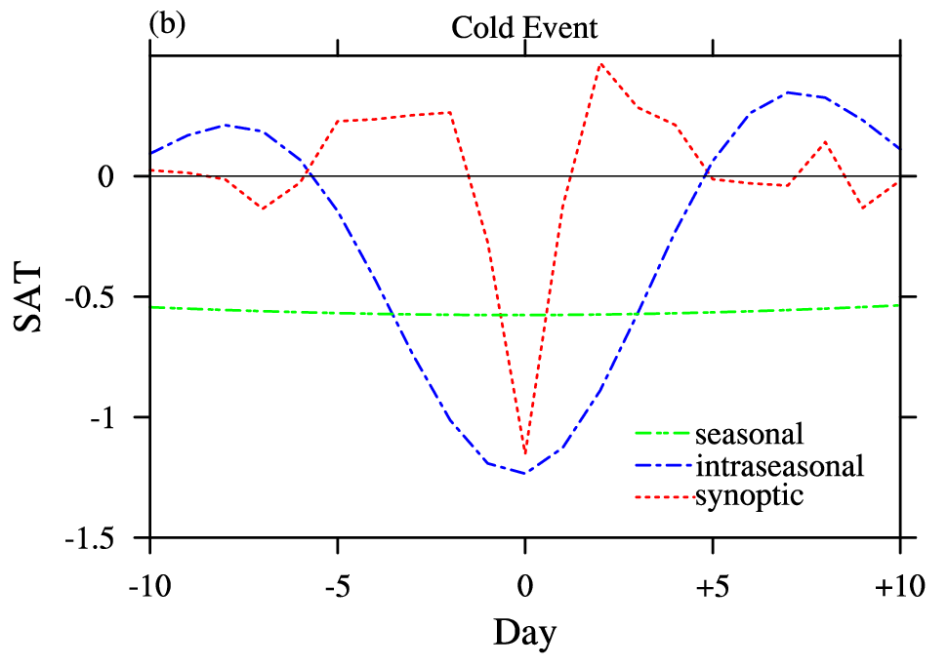

752

753 Fig. 3 The same as Fig. 1 but for the synoptic, intraseasonal, and seasonal components 

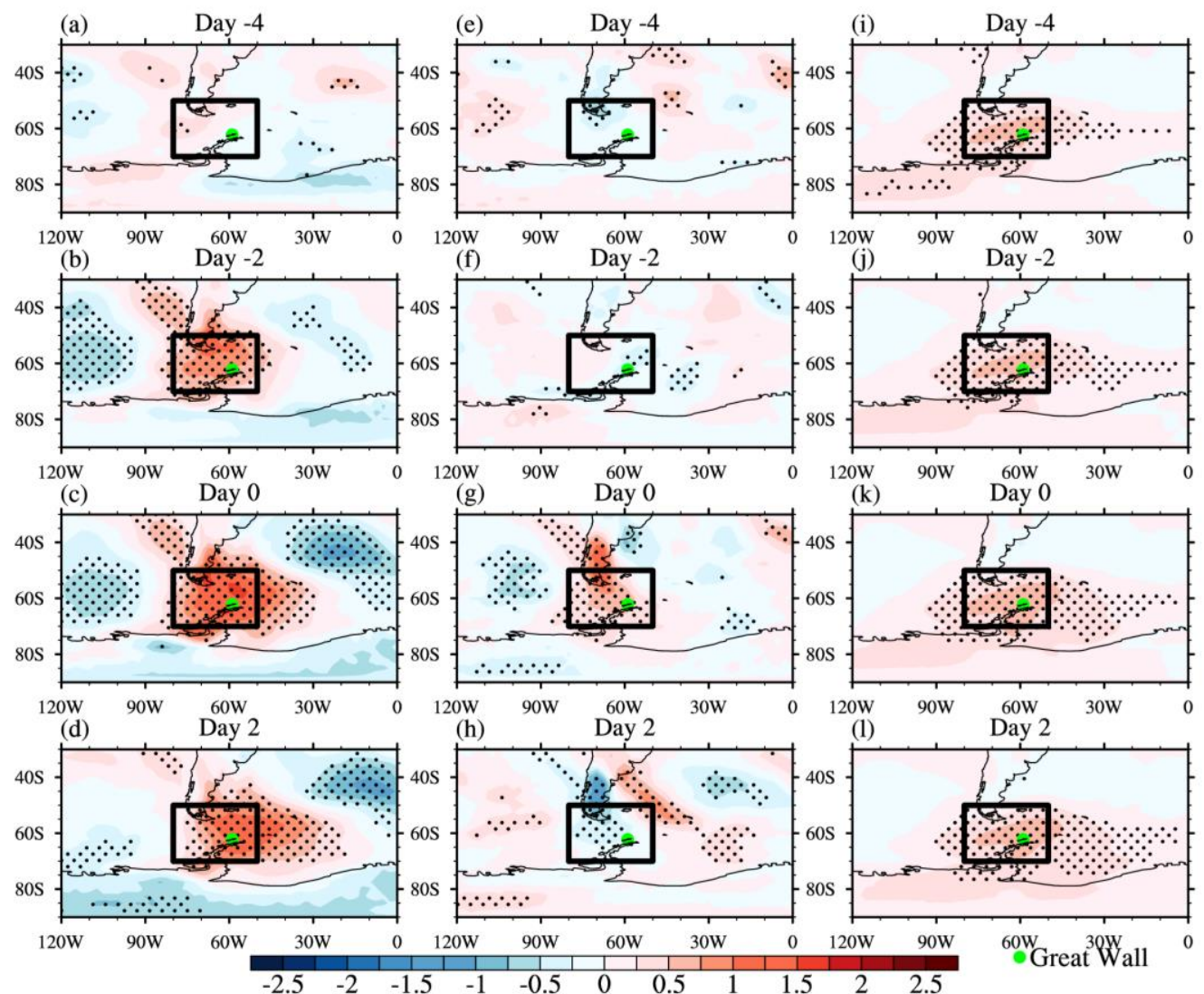

Fig. 4 Composite anomalies of the intraseasonal component of SAT $\left({ }^{\circ} \mathrm{C}\right)$ on days (a) - 

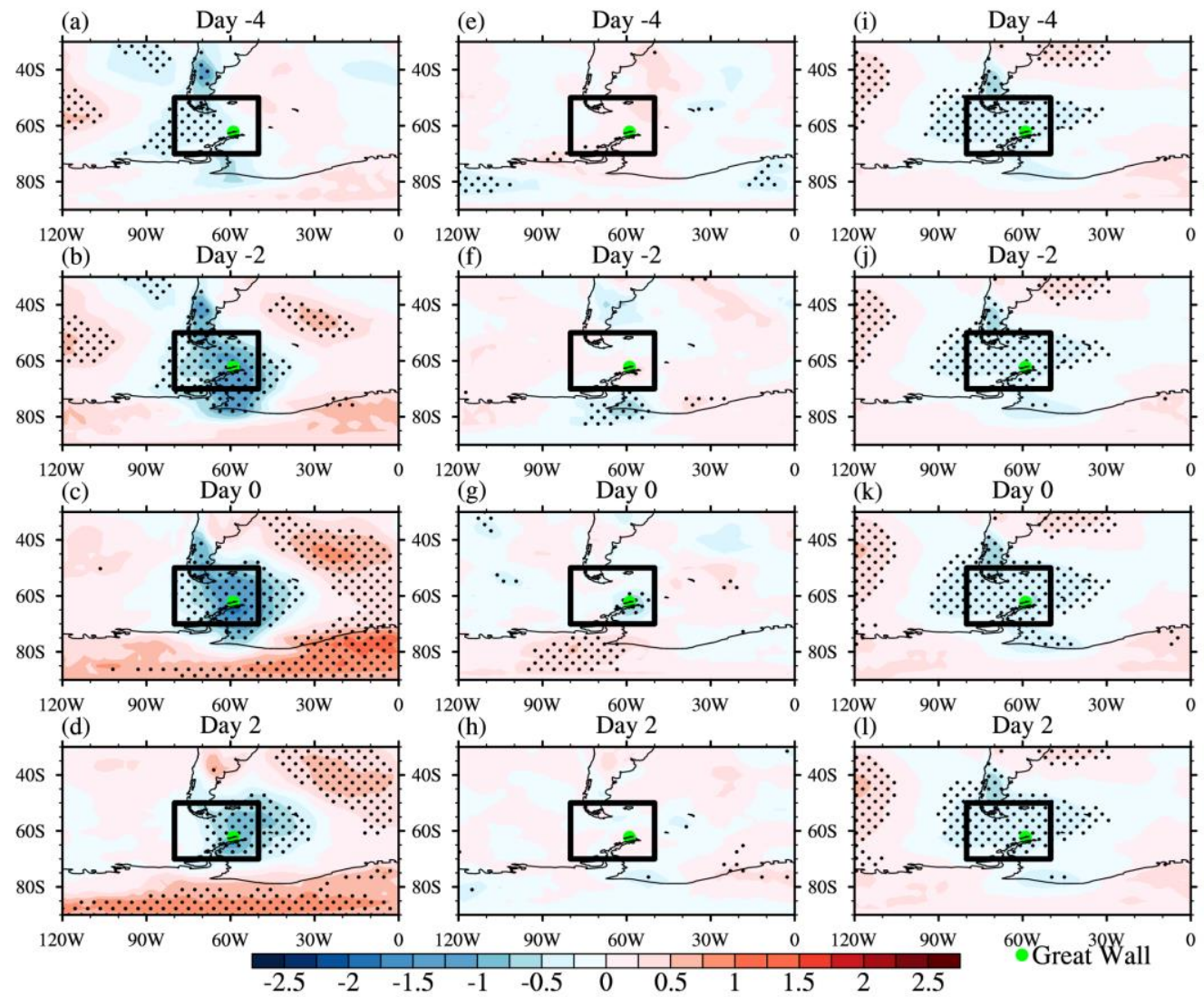

770

Fig. 5 The same as Fig. 4 but for the cold events. 

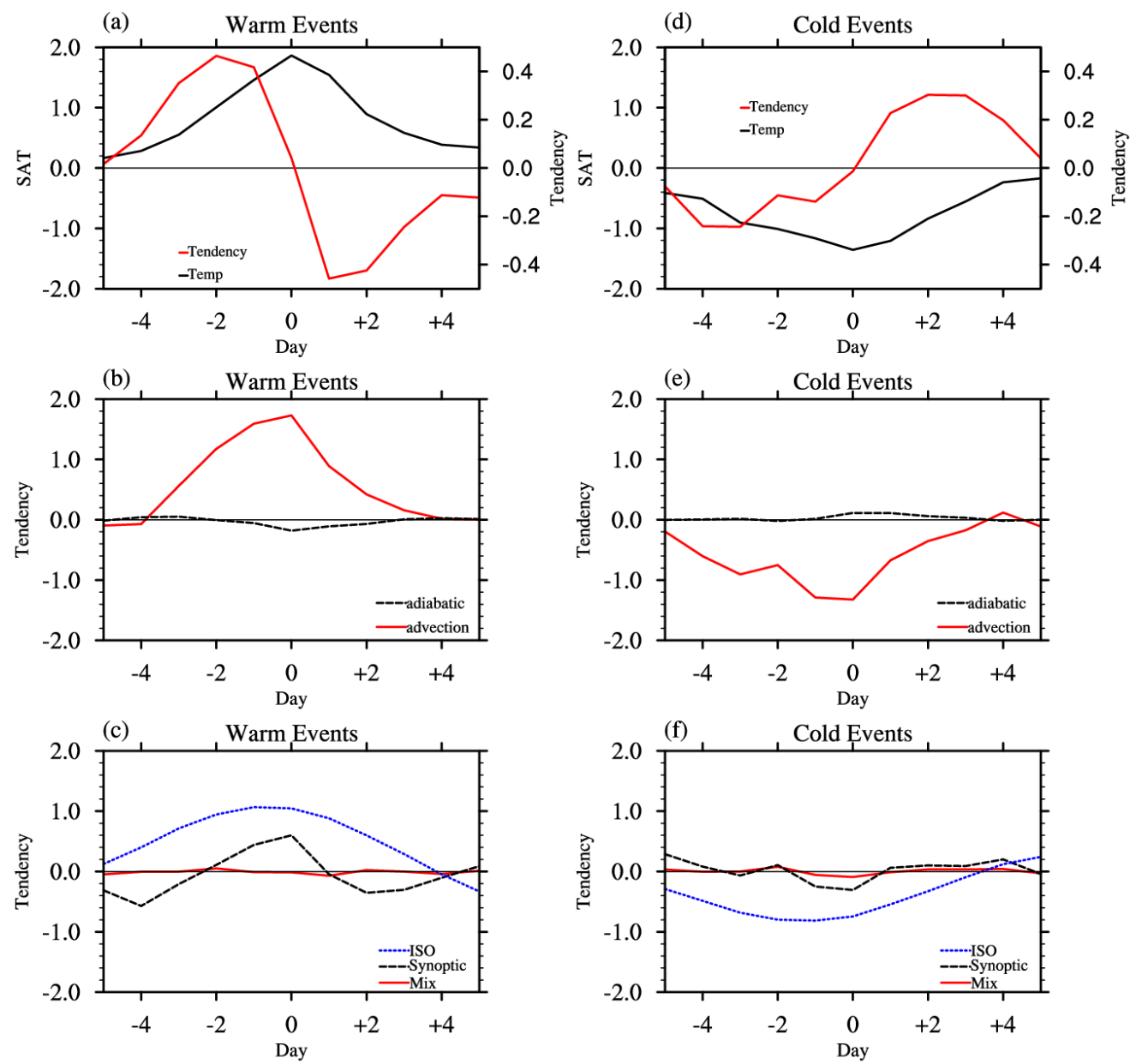

Fig. 6 Time evolution of the composite anomalies of (a) SAT (black line), SAT

(black line) terms and (c) SAT tendency caused by different parts of the advection lag +5 days of the warm events. (d)-(f) are the same as (a)-(c) but for the cold events. 

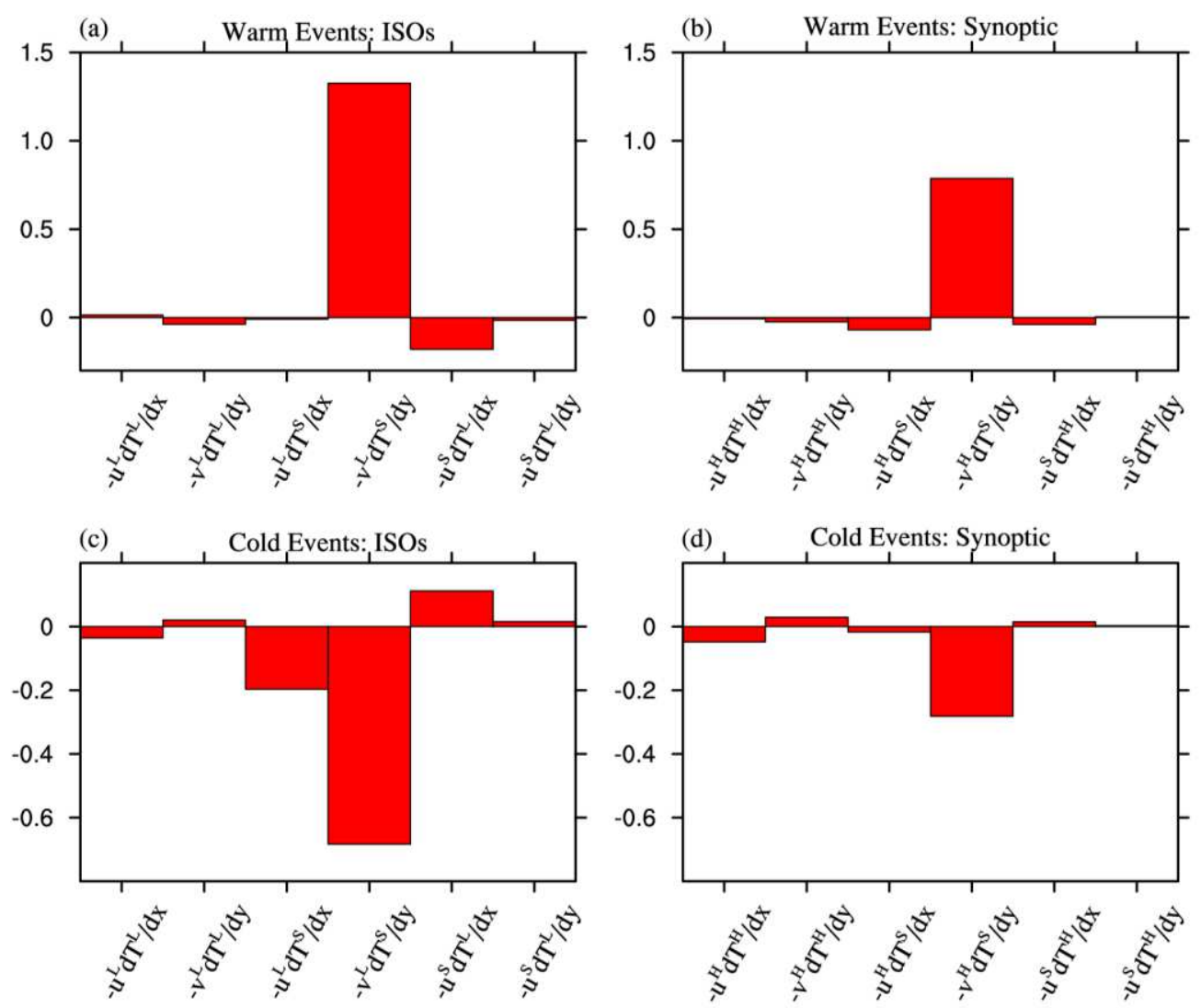

790 Fig. 7 Different parts of advection terms associated with the (a), (c) ISOs and (b), (d) synoptic variations on lag 0 day of the warm and cold events, respectively. 

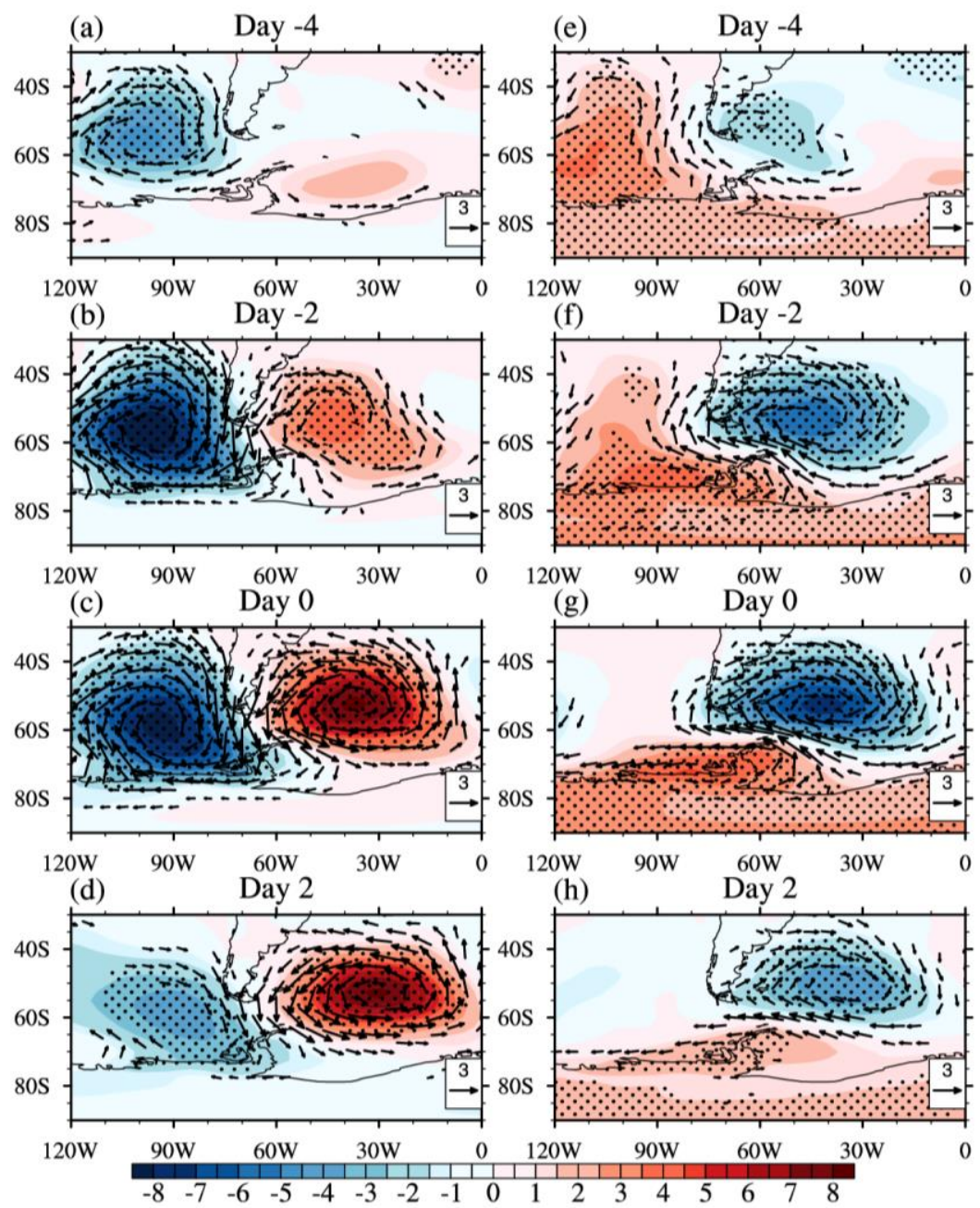

798 Fig. 8 Composite anomalies of intraseasonal components of SLP (hPa) (shading) and surface winds $\left(\mathrm{ms}^{-1}\right)$ (vectors) on days (a) -4 , (b) -2 , (c) 0 and (d) +2 of the warm events. (e)-(h) are the same as (a)-(d) but for the cold events. The dots indicate 
(a) Day -2 of Warm Events
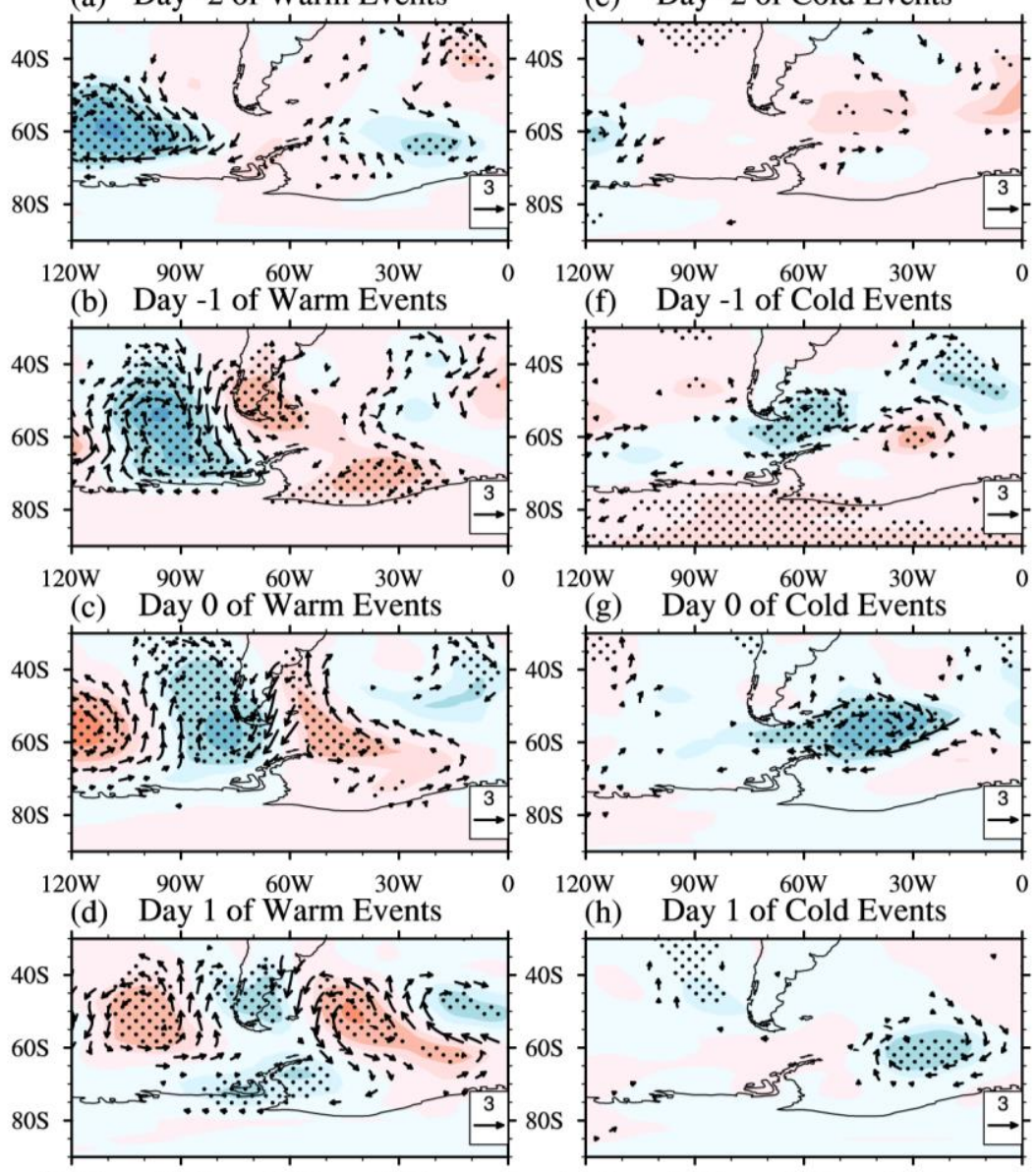

(h) Day 1 of Cold Events

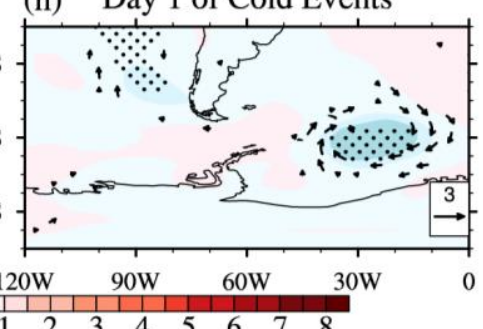

Fig. 9 Composite anomalies of synoptic components of SLP (hPa) (shading) and 

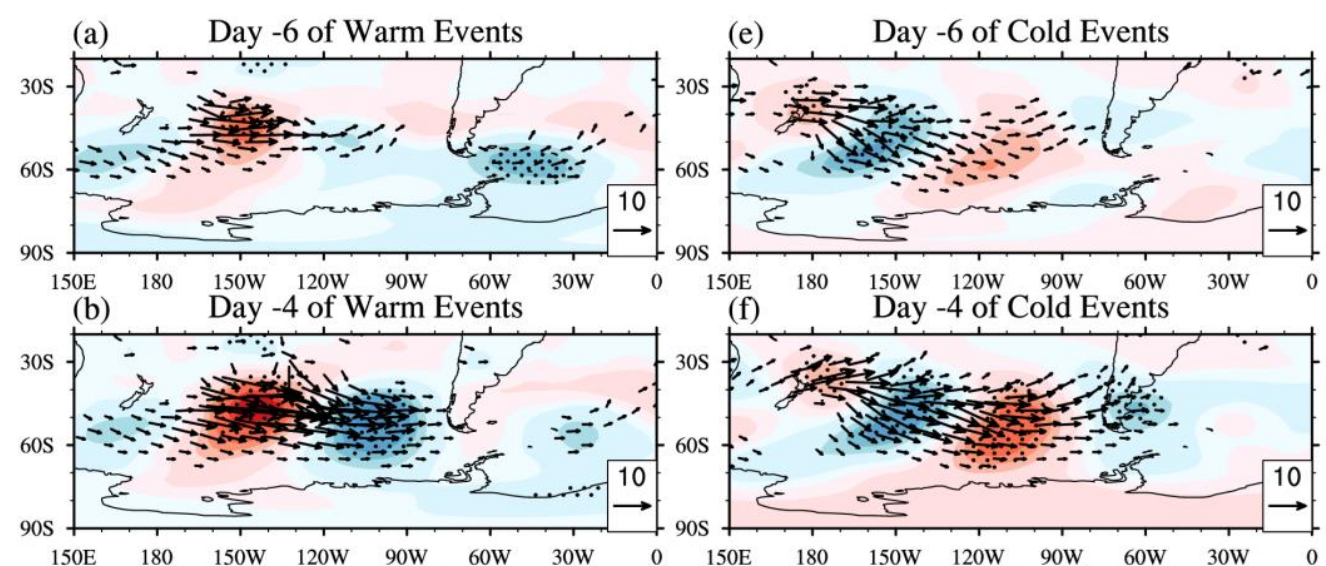

(f)

Day -4 of Cold Events
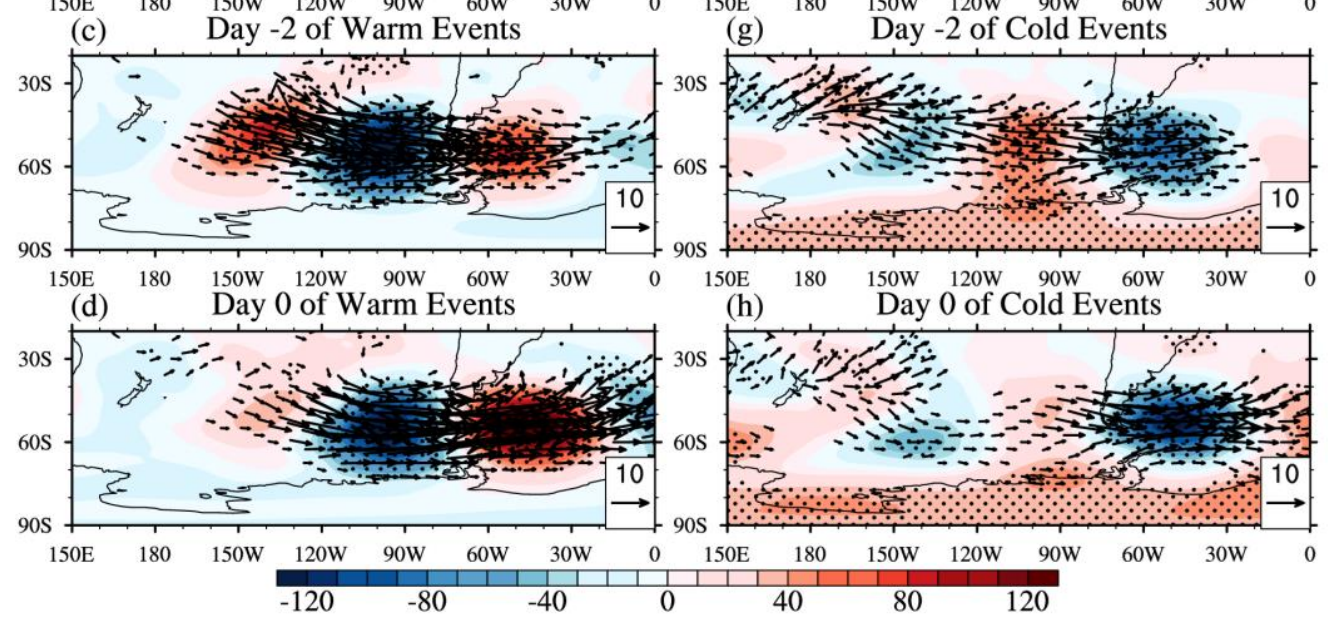

813 Fig. 10 Composite anomalies of the intraseasonal component of geopotential height anomalies at $300 \mathrm{hPa}(\mathrm{m})$ (shading) and the attendant wave activity flux (vector) on days (a) -6 , (b) -4 , (c) -2 and (d) 0 of the warm events. (e)-(h) are the same as (a)-(d) but for the cold events. The dots indicate anomalies significant at the $95 \%$ confidence 

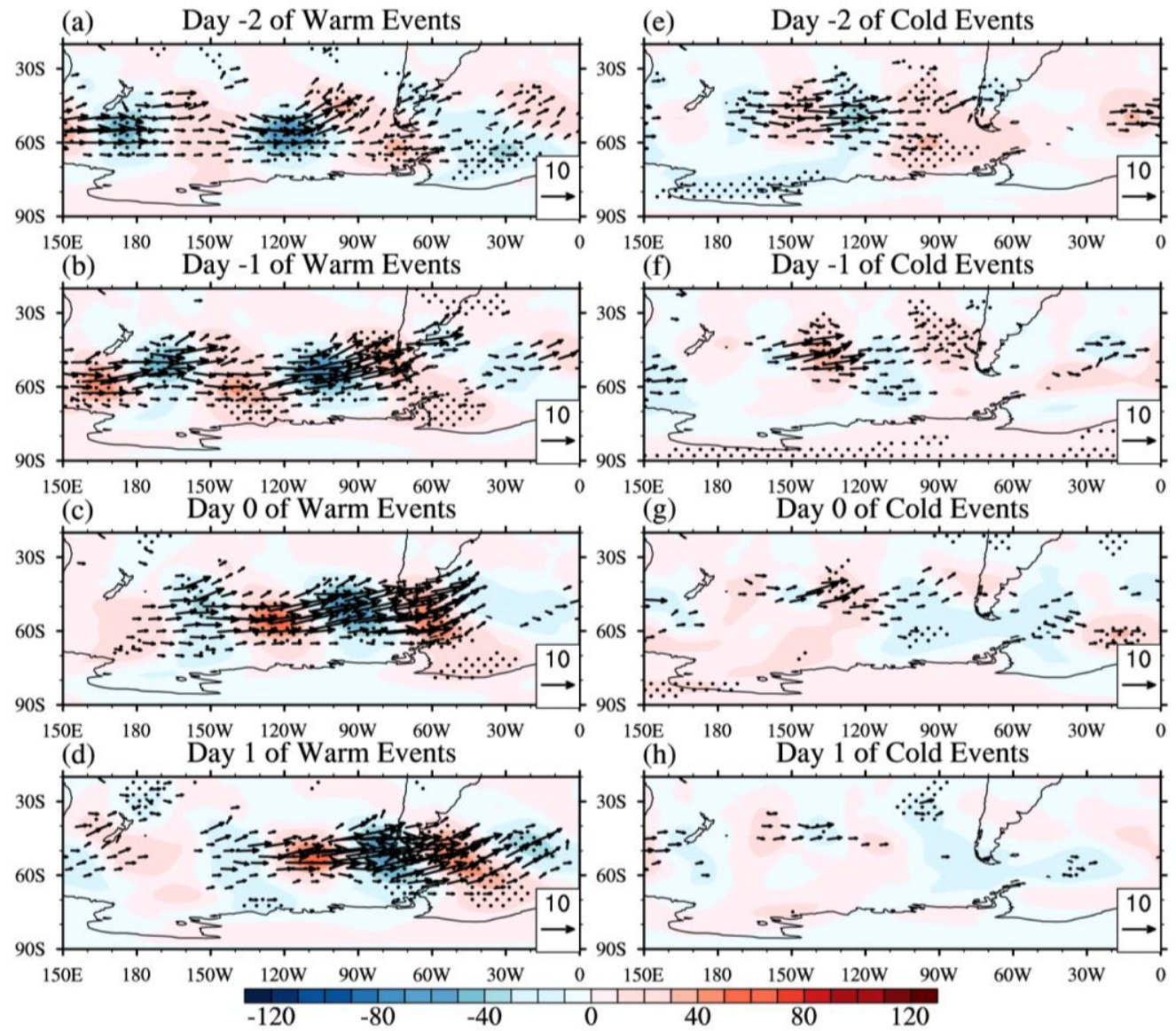

824

Fig. 11 Composite anomalies of the synoptic component of geopotential height anomalies at $300 \mathrm{hPa}(\mathrm{m})$ (shading) and the attendant wave activity flux (vector) on days (a) -2 , (b) -1 , (c) 0 and (d) +1 of the warm events. (e)-(h) are the same as (a)-(d) but for the cold events. The dots indicate anomalies significant at the $95 \%$ confidence level. 

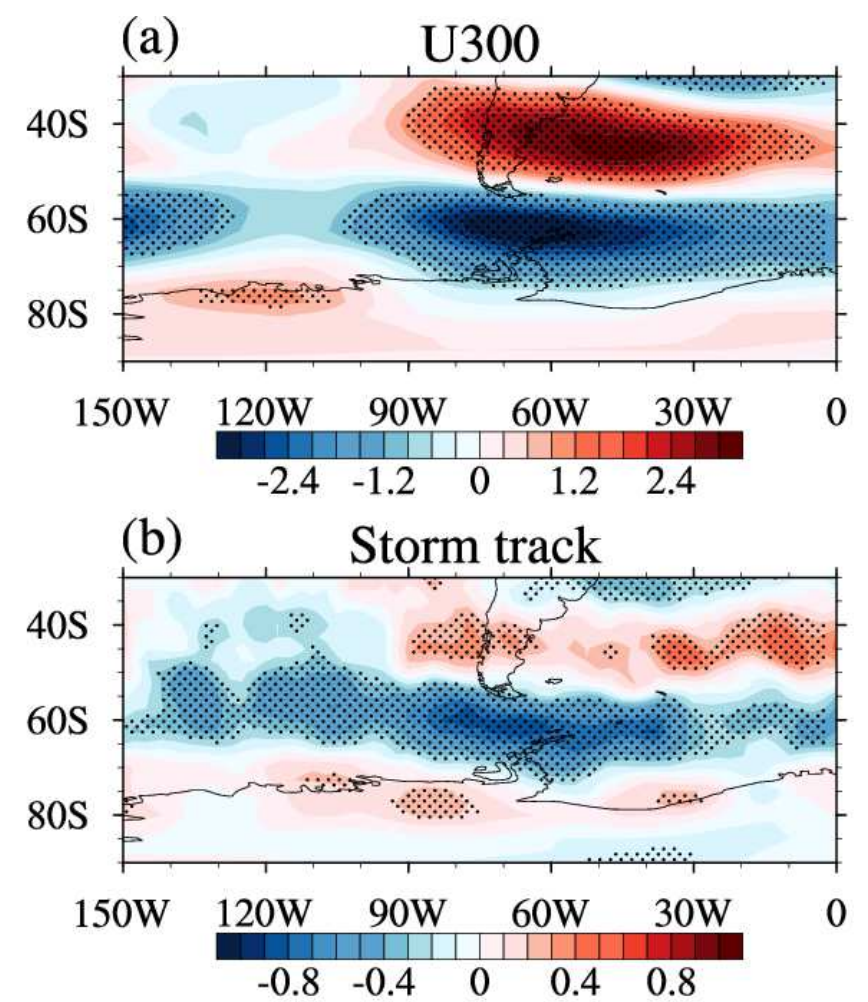

Fig. 12 Composite anomalies of the seasonal component of (a) 300-hPa zonal wind anomalies significant at the $95 \%$ confidence level. 


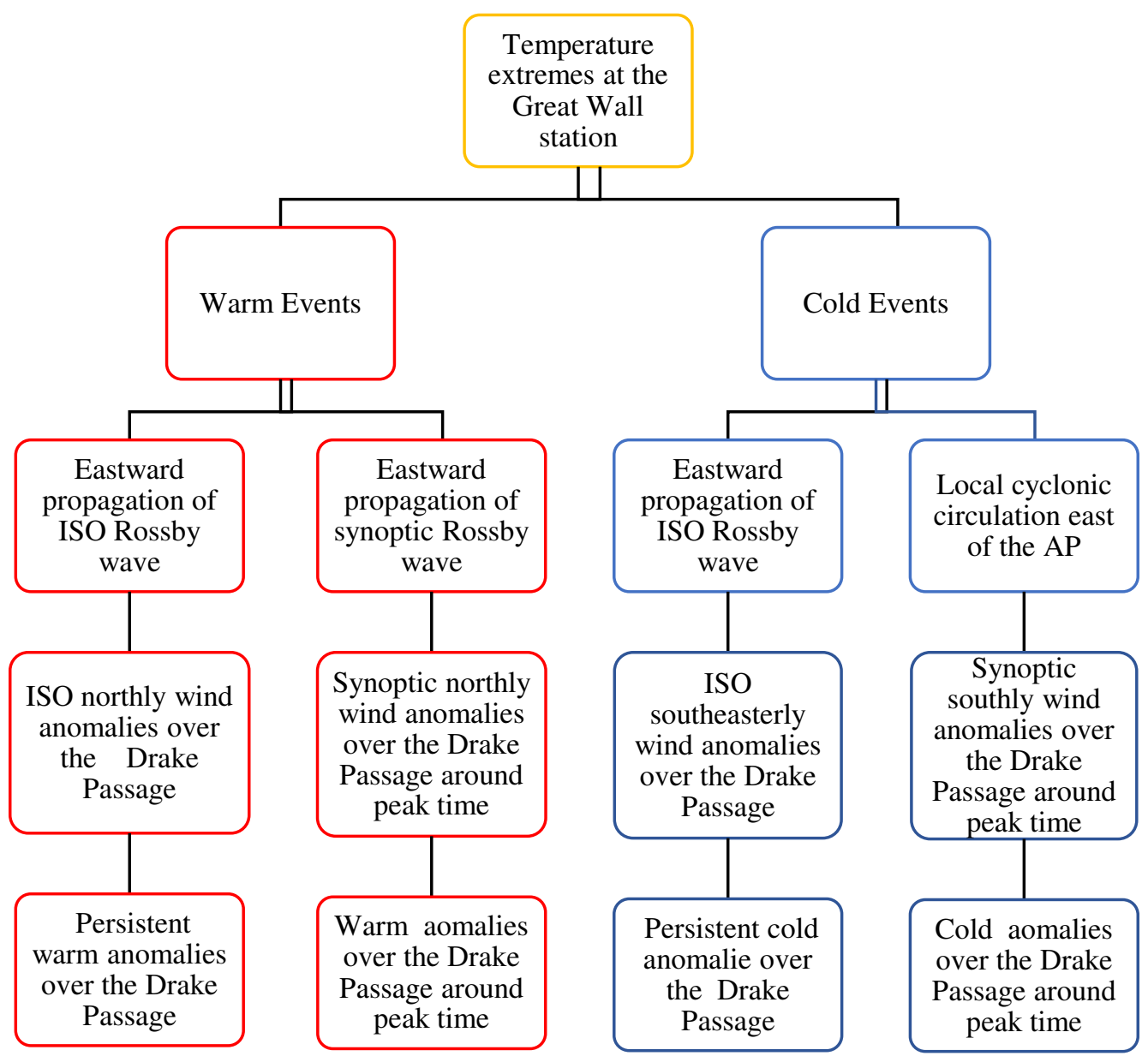

Fig. 13 Schematic illustration of the role of atmospheric flow in the formation 
Figures
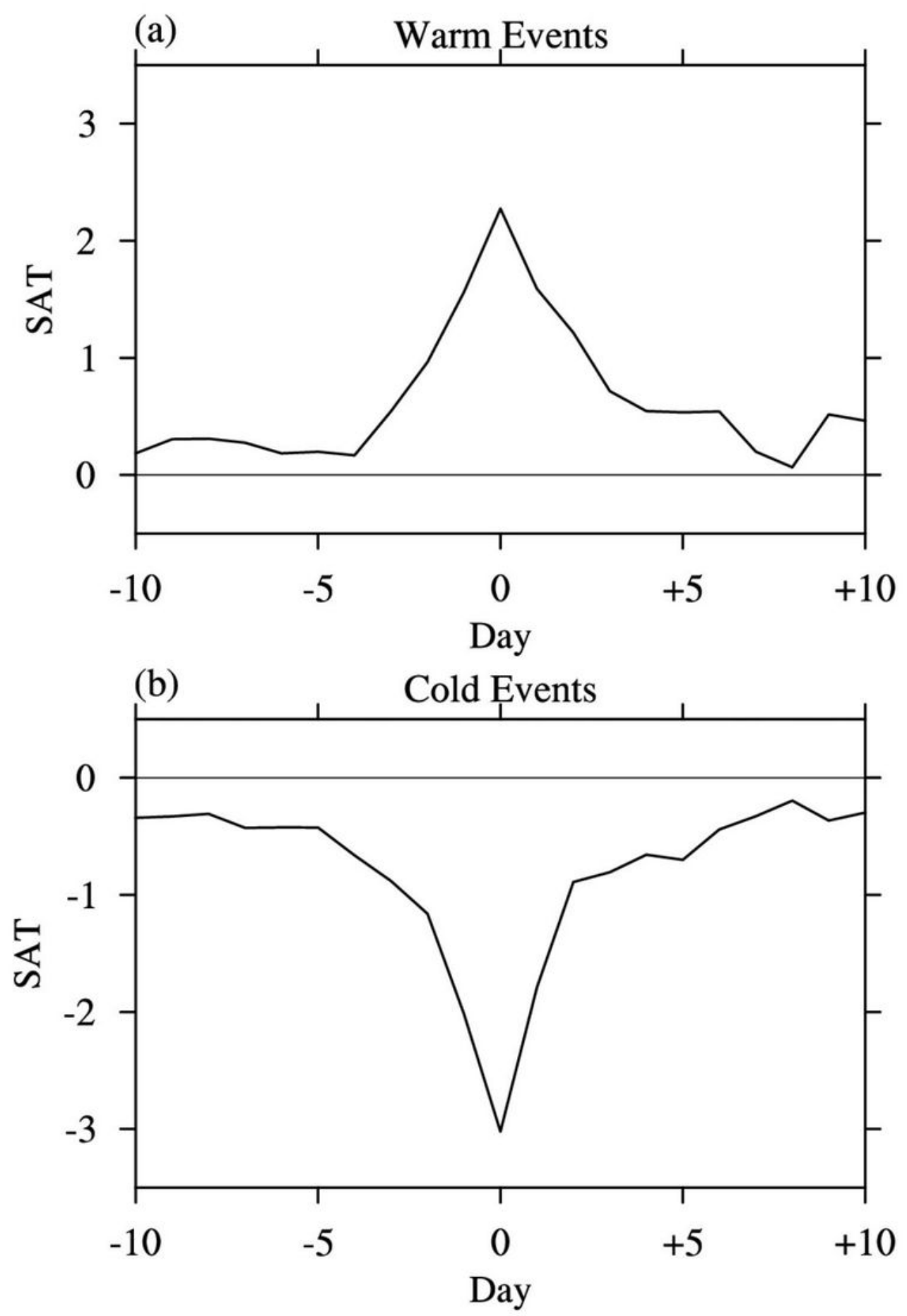

\section{Figure 1}

Time evolution of surface air temperature (SAT) anomalies $\left({ }^{\circ} \mathrm{C}\right)$ at the Great Wall Station during lag - 10 to lag +10 days of (a) warm and (b) cold events. 

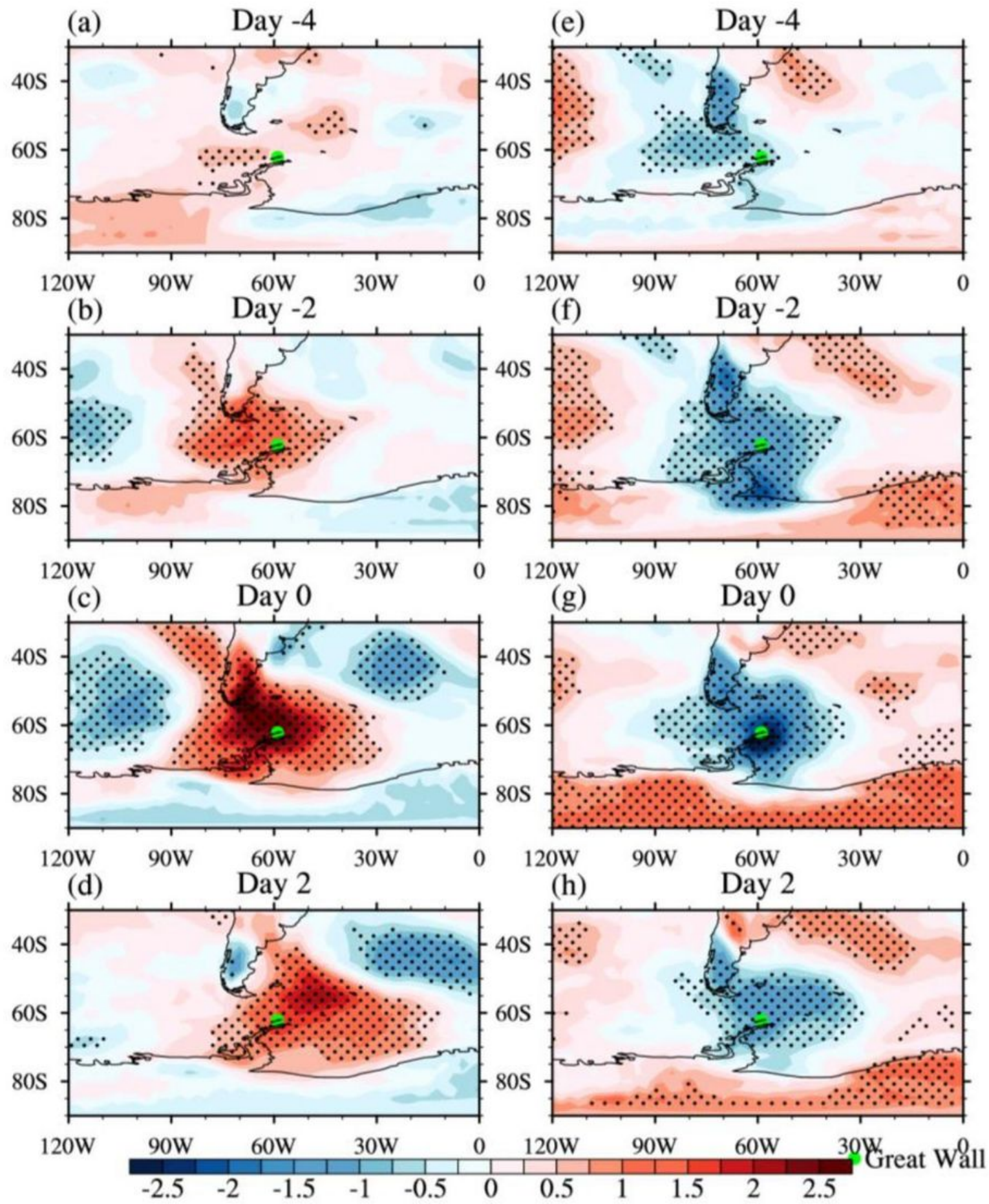

\section{Figure 2}

Composite SAT anomalies ( ${ }^{\circ} \mathrm{C}$ ) on days (a) -4 , (b) -2 , (c) 0 and (d) +2 of the warm events. (e)-(h) are the same as (a)-(d) but for cold events. The dots indicate anomalies significant at the $95 \%$ confidence level. The green dot indicates the location of the Great Wall Station. 

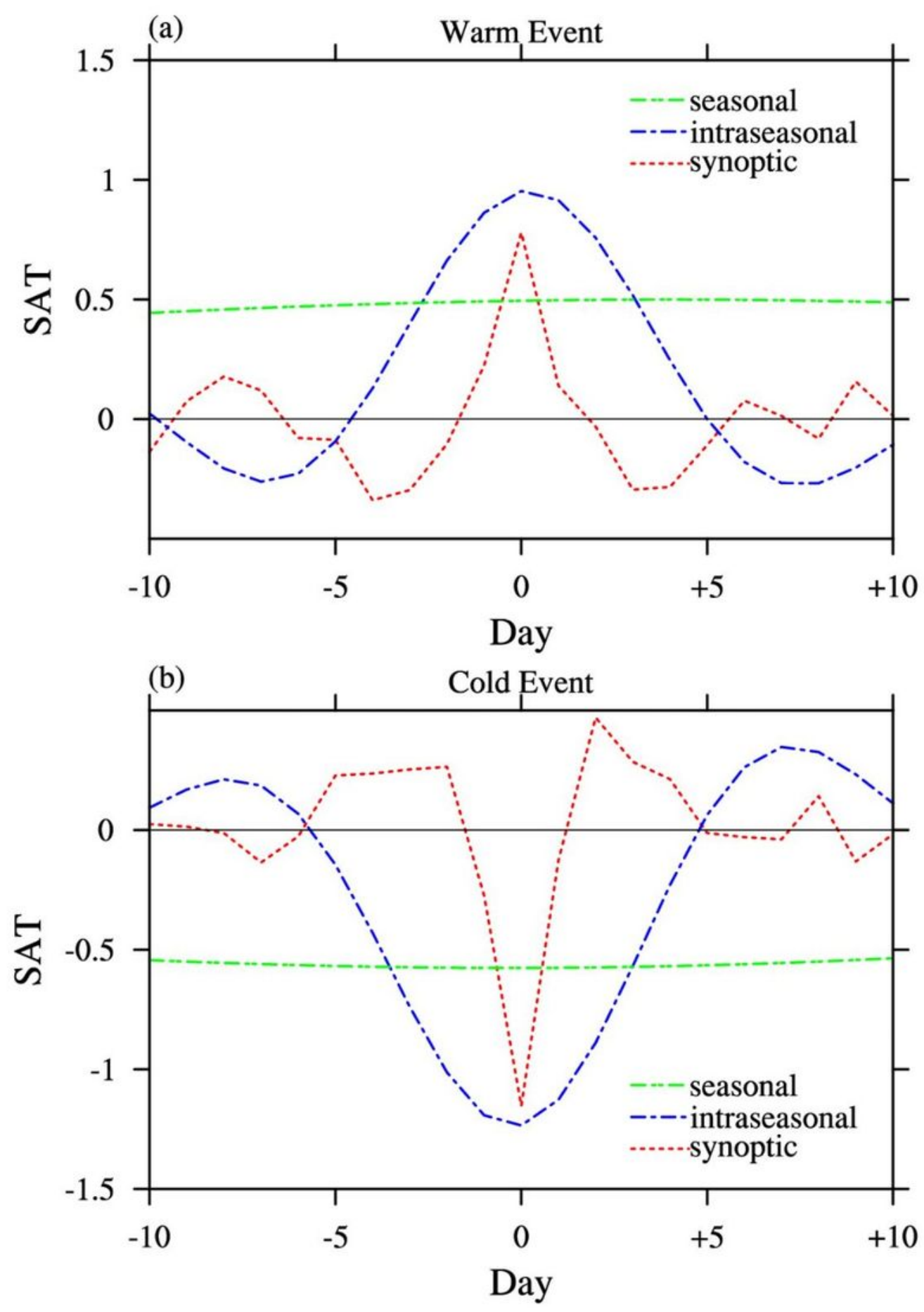

Figure 3

The same as Fig. 1 but for the synoptic, intraseasonal, and seasonal components of SAT. 

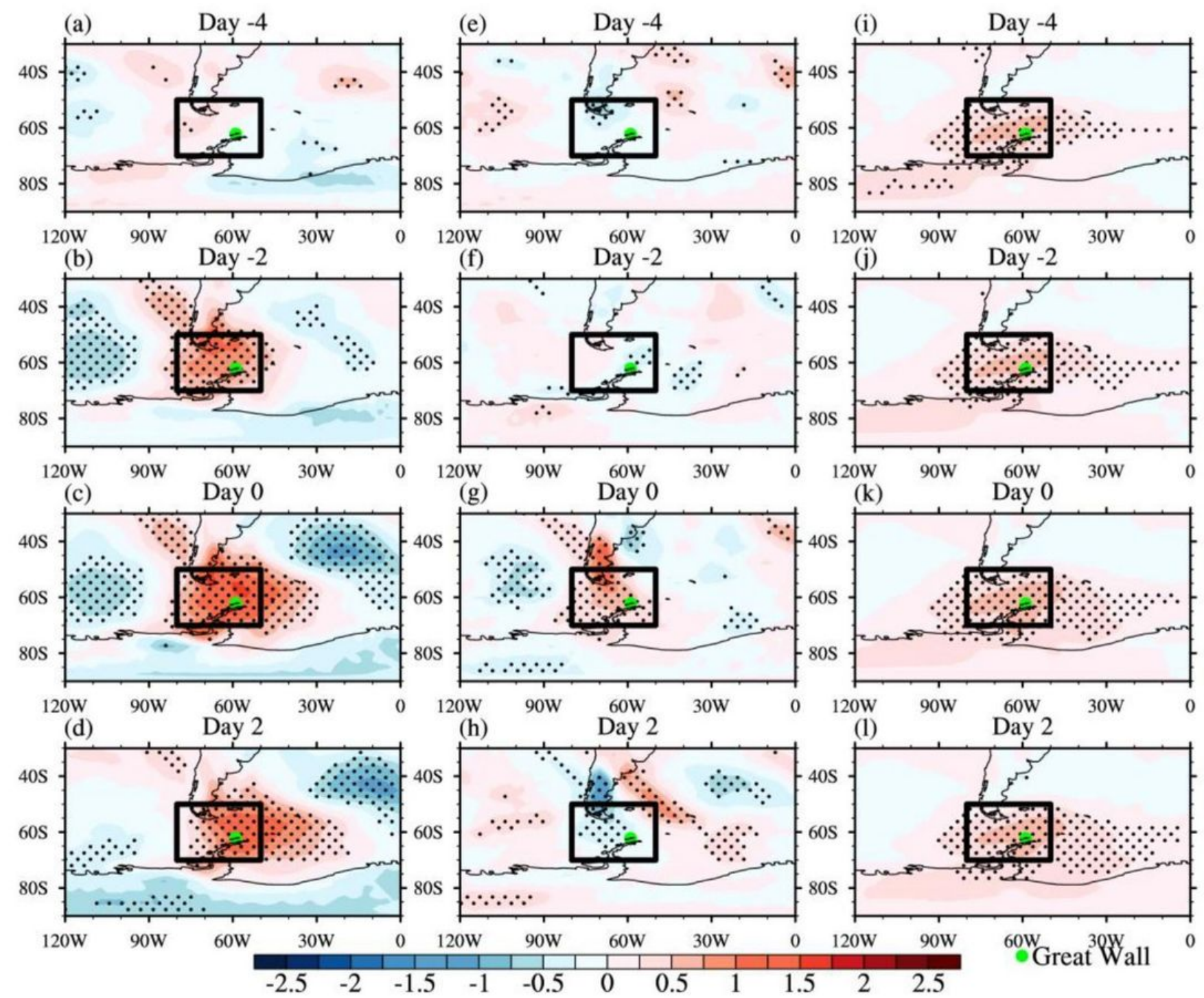

(h) Day 2

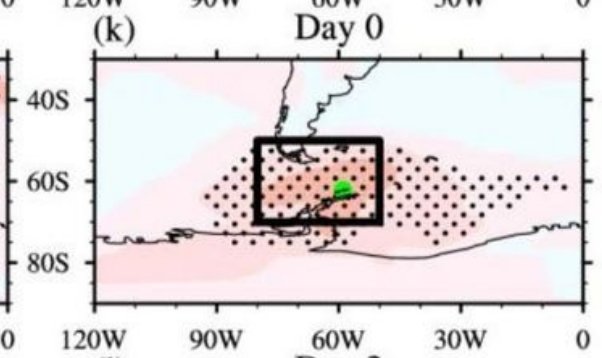

\section{Figure 4}

Composite anomalies of the intraseasonal component of SAT ( ${ }^{\circ} \mathrm{C}$ ) on days (a) -4 , (b) -2 , (c) 0 and (d) +2 of the warm events. (e)-(h) and (i)-(l) are the same as (a)-(d) but for the synoptic and seasonal components of SAT, respectively. The dots indicate anomalies significant at the $95 \%$ confidence level. The green dot indicates the location of the Great Wall Station. 

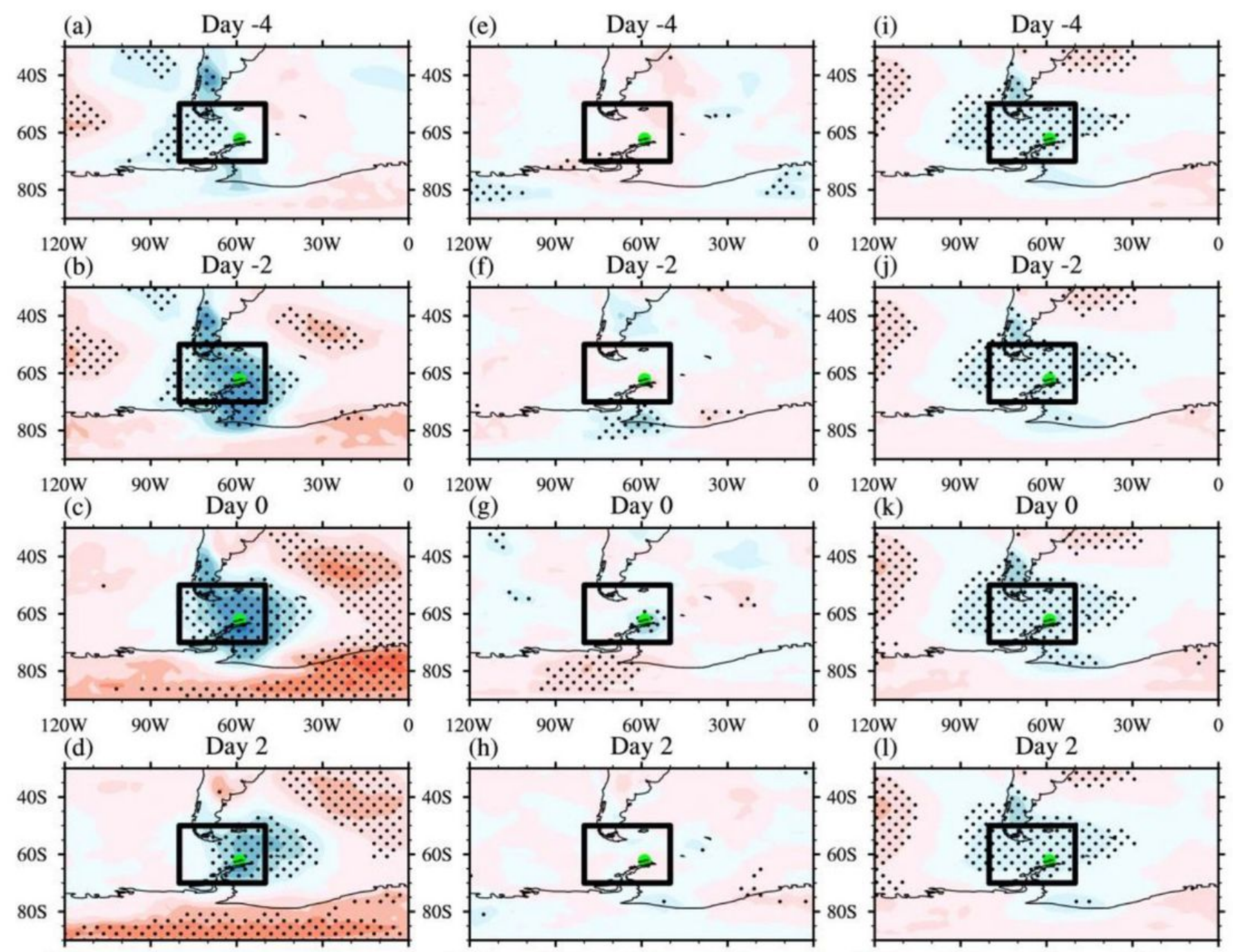

(h)
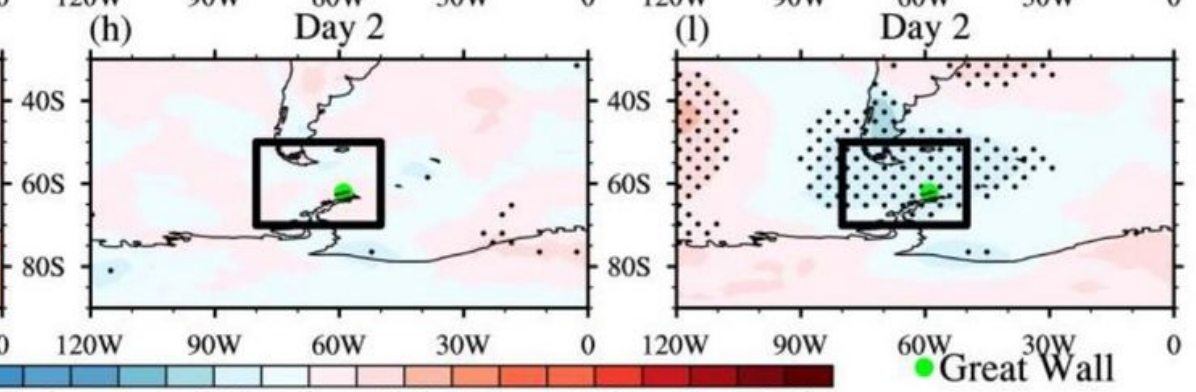

\section{Figure 5}

The same as Fig. 4 but for the cold events. 

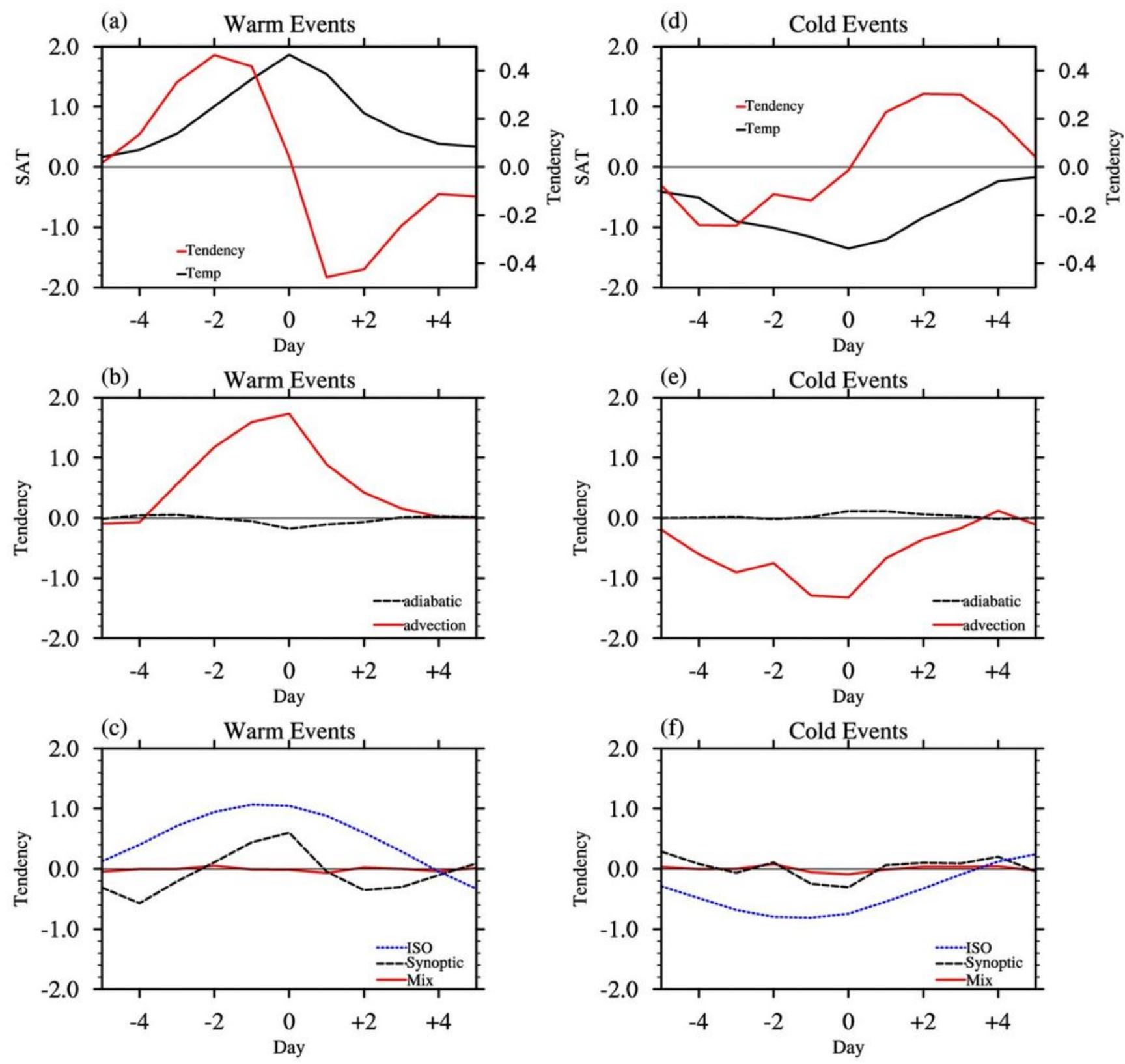

\section{Figure 6}

Time evolution of the composite anomalies of (a) SAT (black line), SAT tendency (red line), (b) SAT tendency induced by advection (red line) and adiabatic (black line) terms and (c) SAT tendency caused by different parts of the advection term averaged over the Drake Passage $\left(70^{\circ} \mathrm{S}-50^{\circ} \mathrm{S}\right.$ and $\left.80^{\circ} \mathrm{W}-50^{\circ} \mathrm{W}\right)$ during lag -5 to lag +5 days of the warm events. (d)-(f) are the same as (a)-(c) but for the cold events. 

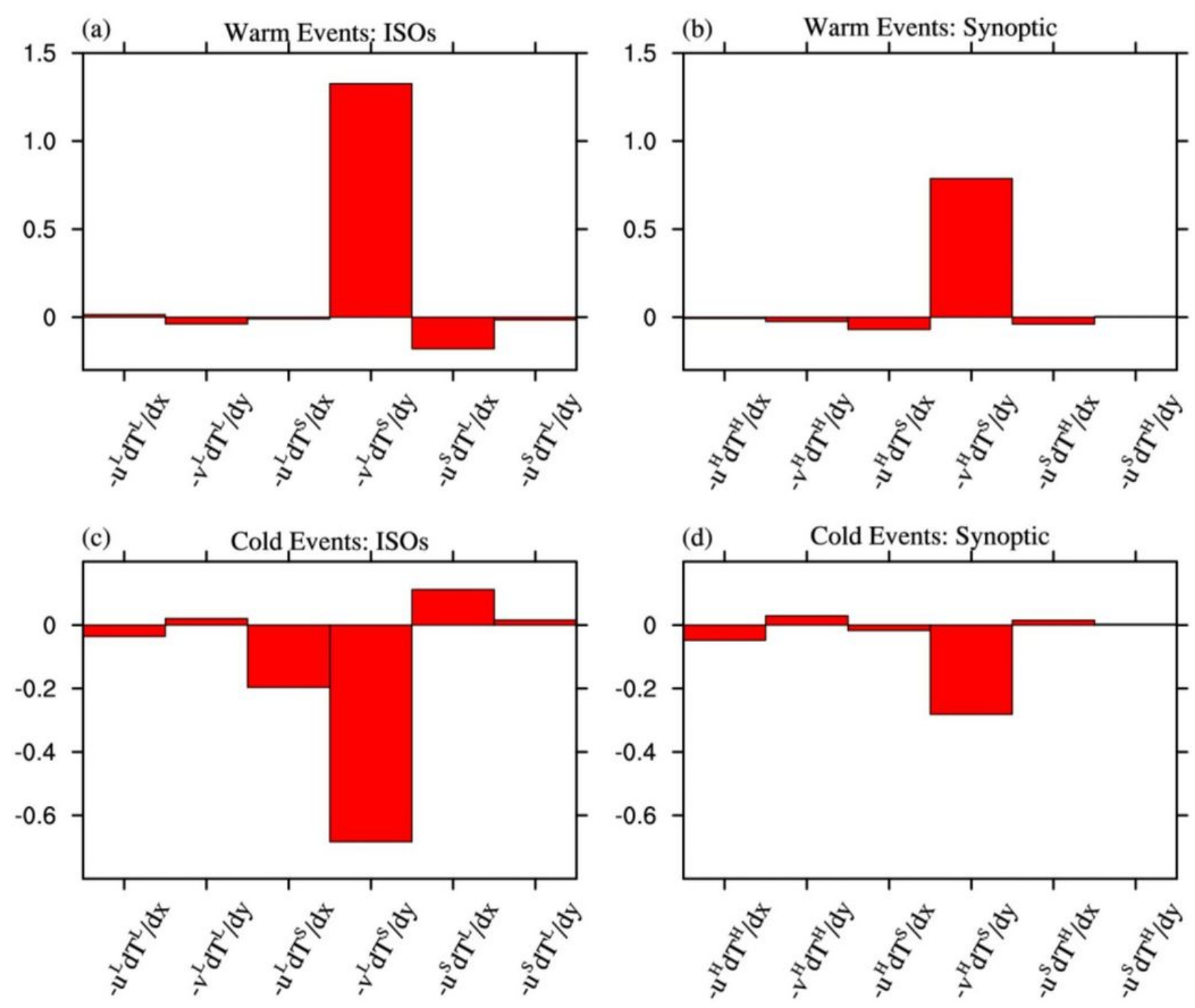

Figure 7

Different parts of advection terms associated with the (a), (c) ISOs and (b), (d) synoptic variations on lag 0 day of the warm and cold events, respectively. 

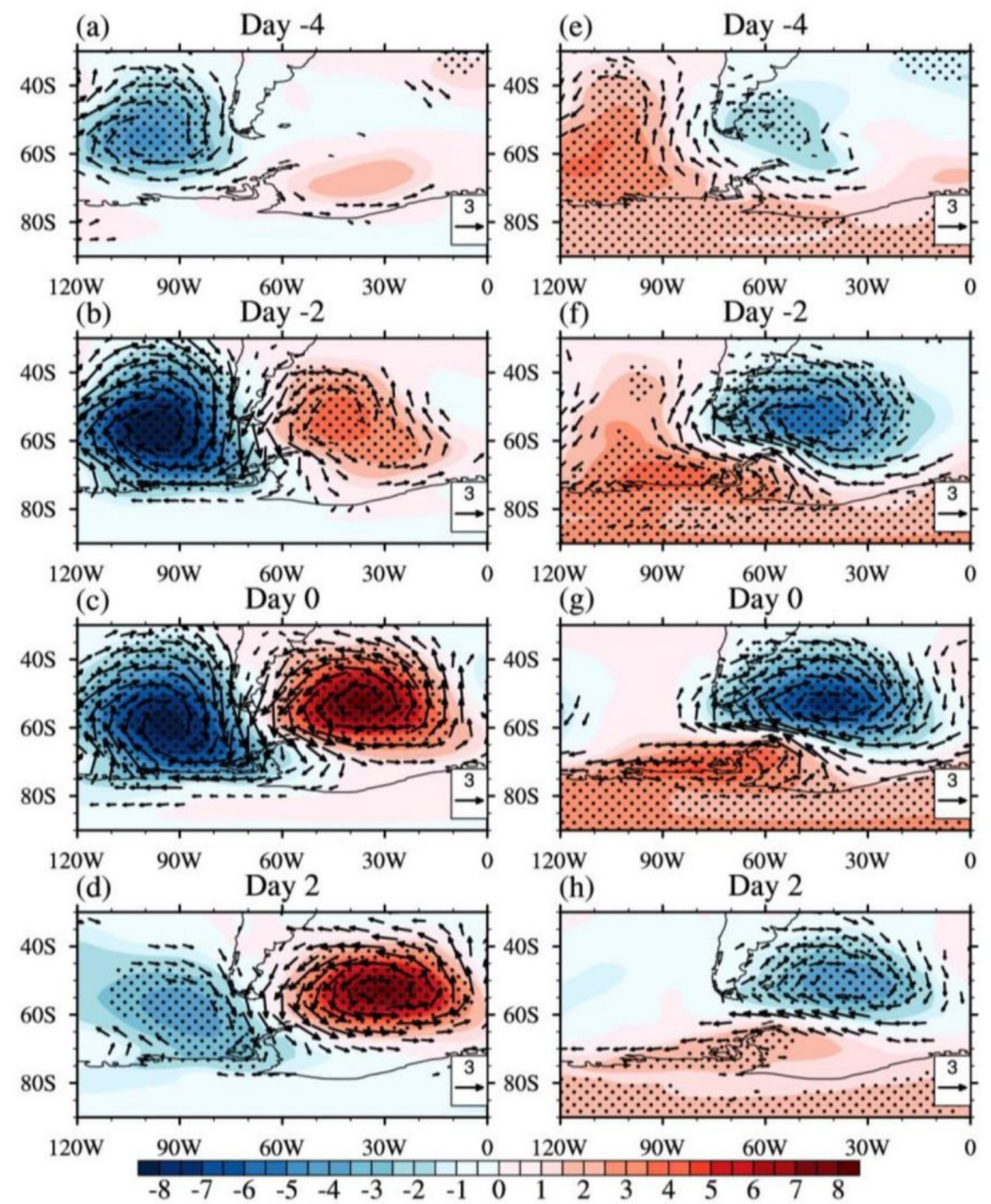

Figure 8

Composite anomalies of intraseasonal components of SLP (hPa) (shading) and surface winds (ms-1) (vectors) on days (a) -4, (b) -2, (c) 0 and (d) +2 of the warm events. (e)-(h) are the same as (a)-(d) but for the cold events. The dots indicate anomalies significant at the $95 \%$ confidence level. 
(a) Day -2 of Warm Events

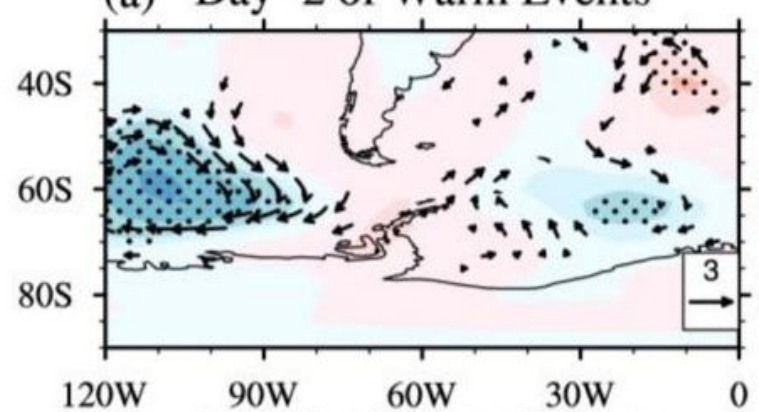

(e) Day -2 of Cold Events

(b) Day -1 of Warm Events
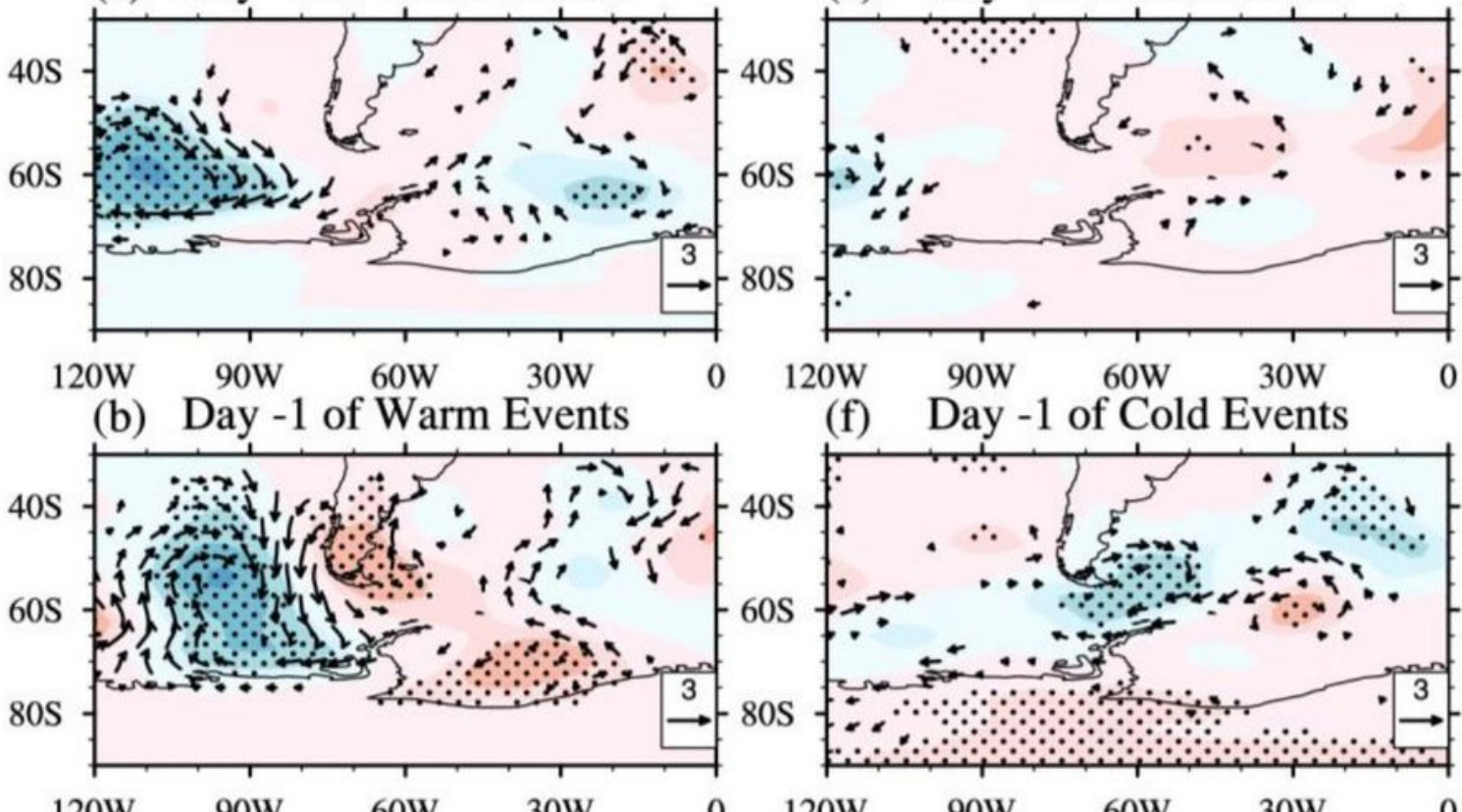

(f) Day -1 of Cold Events

(c) Day 0 of Warm Events

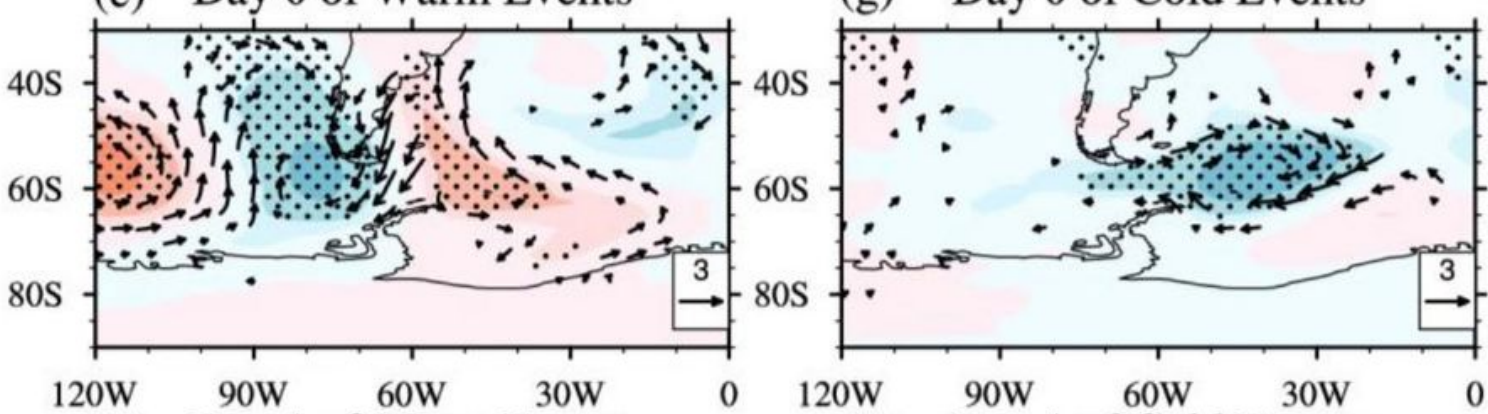

(d) Day 1 of Warm Events

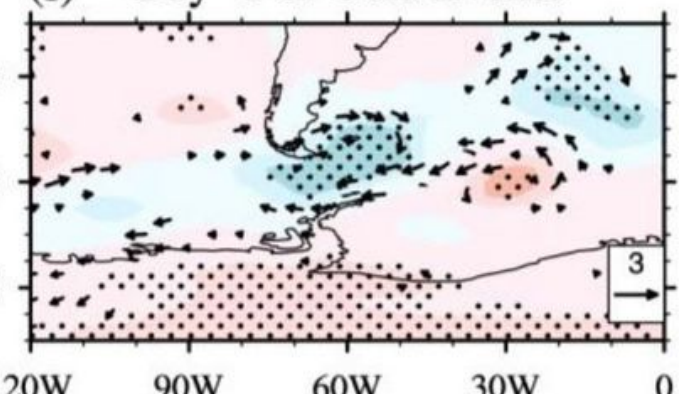

(g) Day 0 of Cold Events

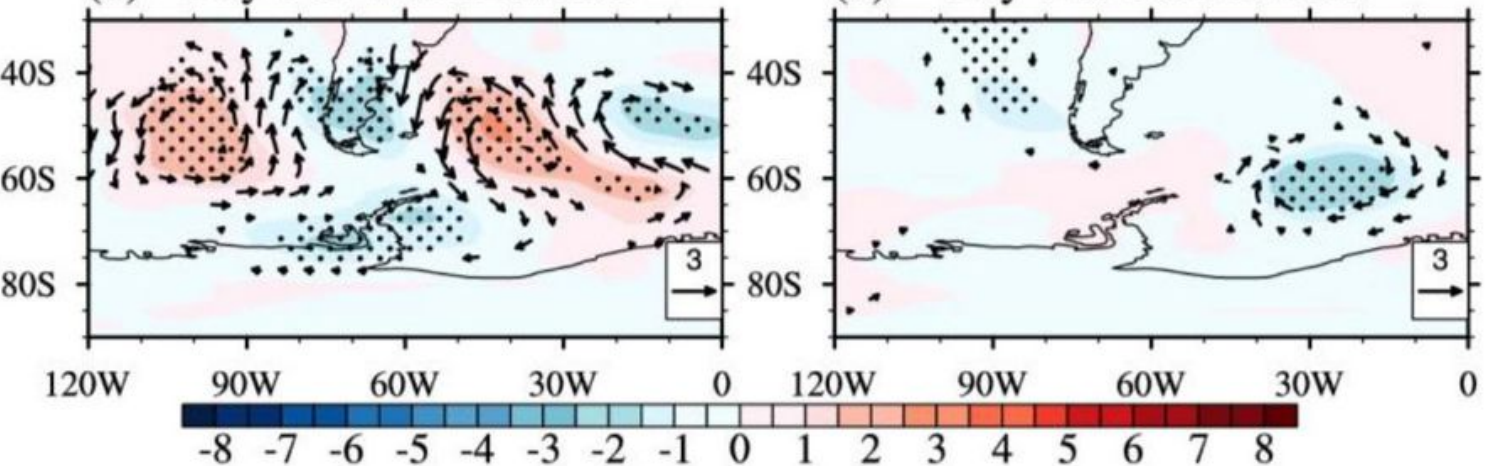

Figure 9

Composite anomalies of synoptic components of SLP (hPa) (shading) and surface winds (ms-1) (vectors) on days (a) -2, (b) - 1 , (c) 0 and (d) +1 of the warm events. (e)-(h) are the same as (a)-(d) but for the cold events. The dots indicate anomalies significant at the $95 \%$ confidence level. 
(a) Day -6 of Warm Events

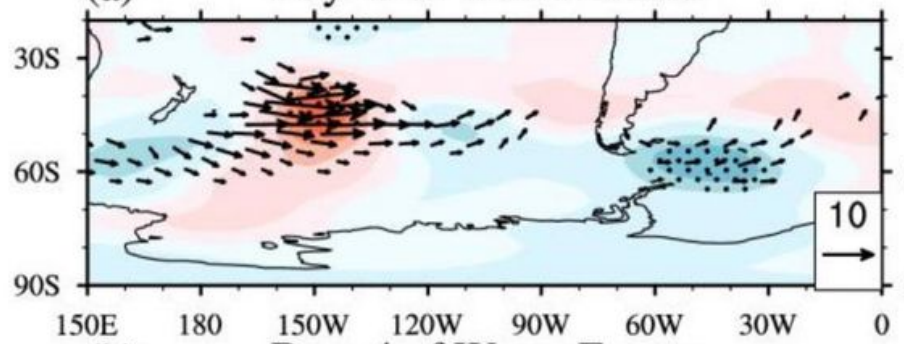

(b)
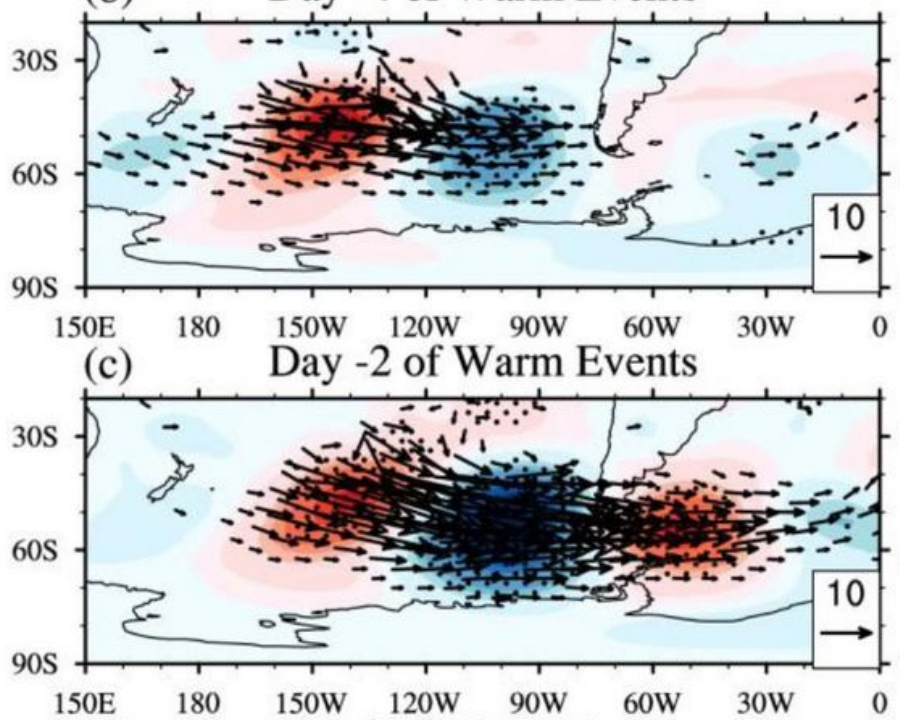

(d) Day 0 of Warm Events (e)

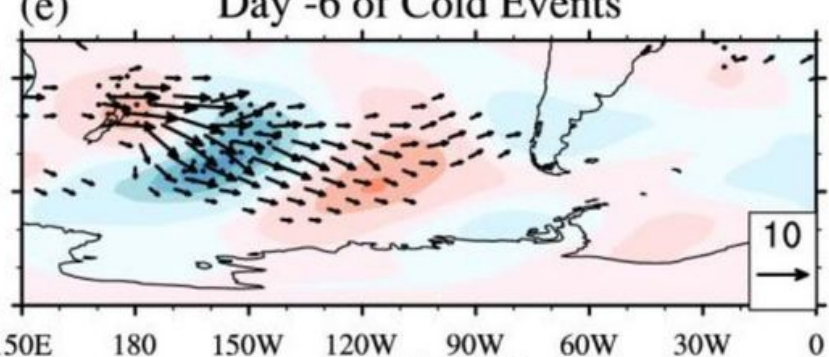

(f)

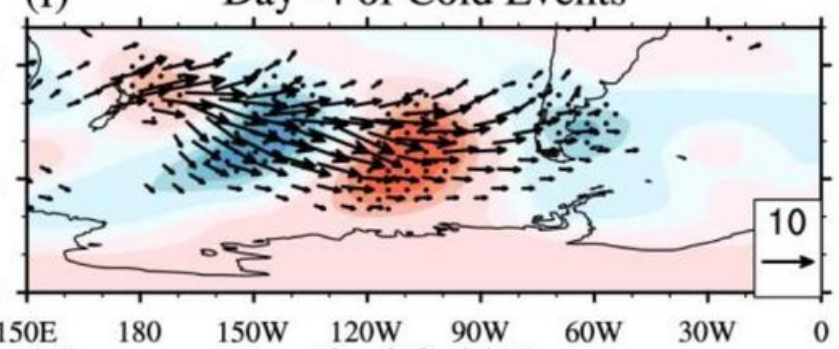

(g) Day -2 of Cold Events

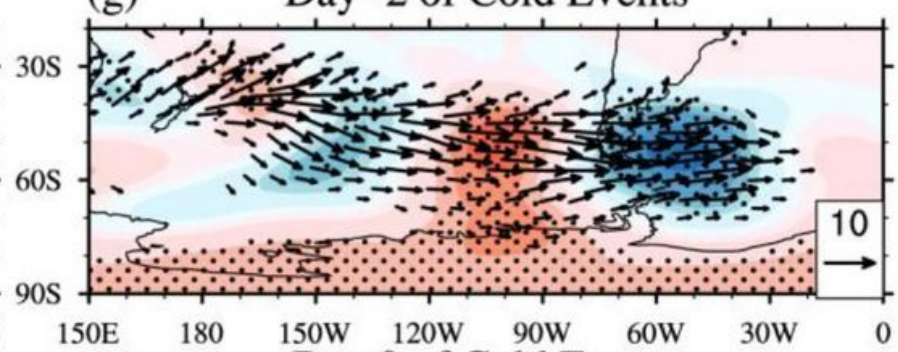

(h)

Day 0 of Cold Events

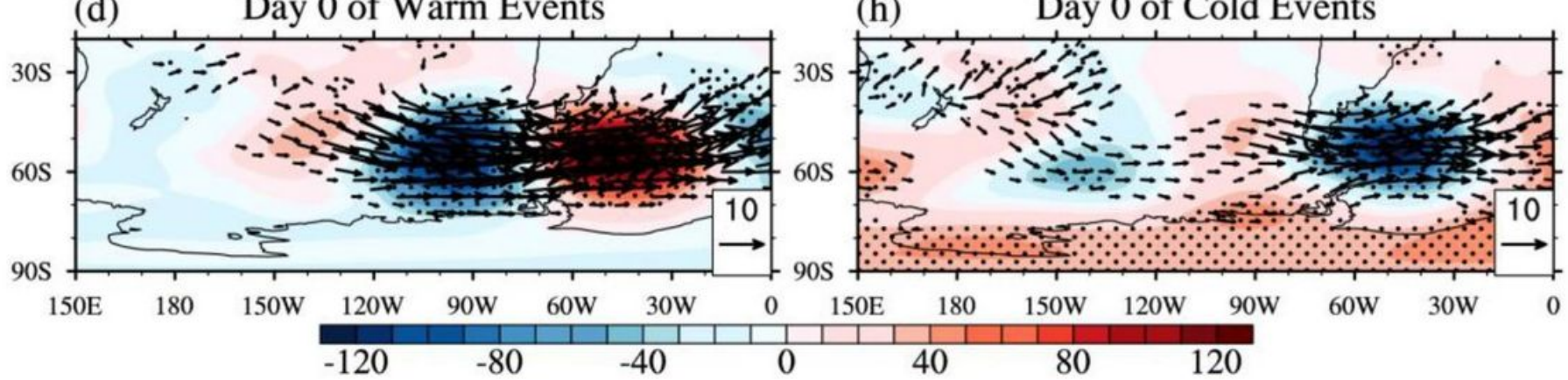

Figure 10

Composite anomalies of the intraseasonal component of geopotential height anomalies at $300 \mathrm{hPa}(\mathrm{m})$ (shading) and the attendant wave activity flux (vector) on days (a) -6, (b) -4, (c) -2 and (d) 0 of the warm events. (e)-(h) are the same as (a)-(d) but for the cold events. The dots indicate anomalies significant at the $95 \%$ confidence level. 
(a)

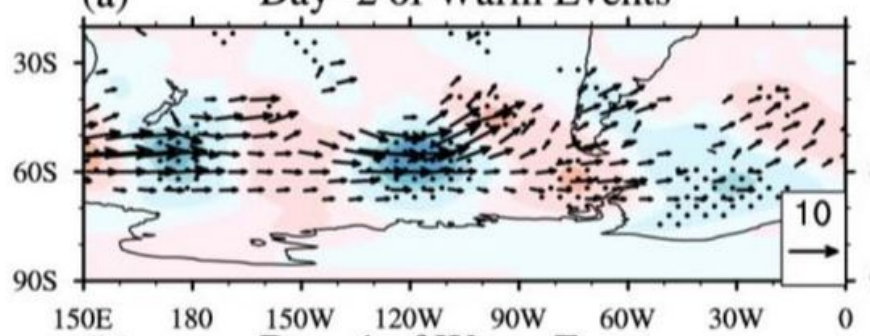

(b)

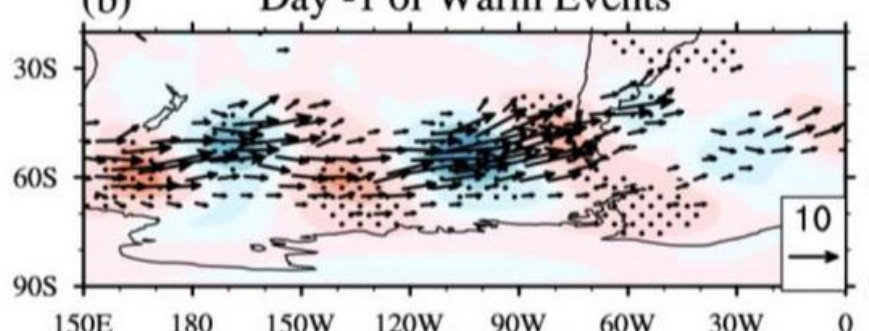

(c)

Day -2 of Warm Events

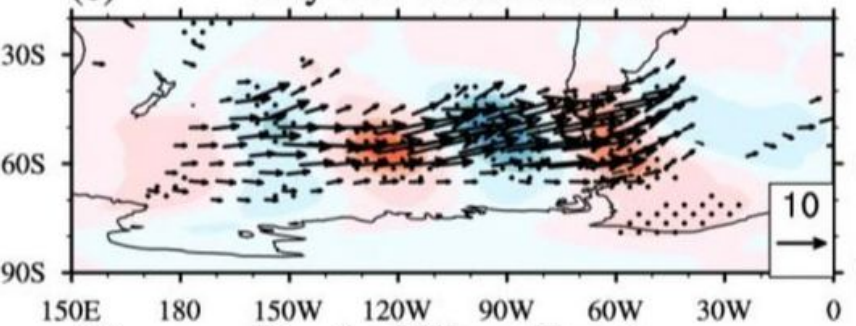

(d)

Day 1 of Warm Events

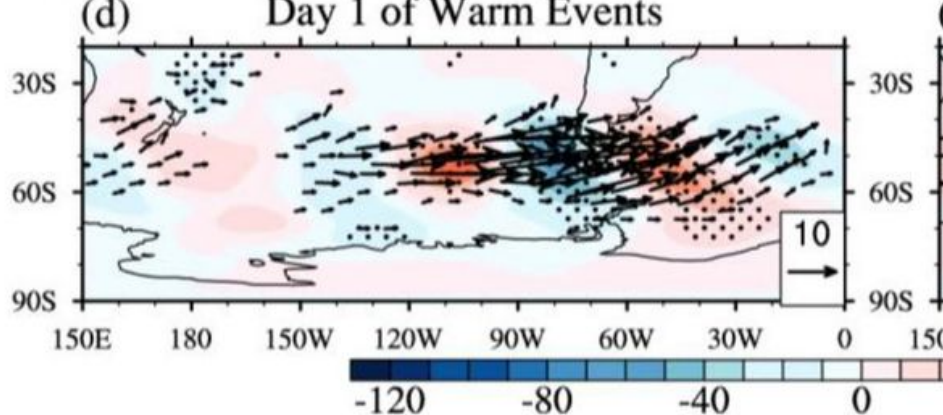

(e) Day - 2 of Cold Events

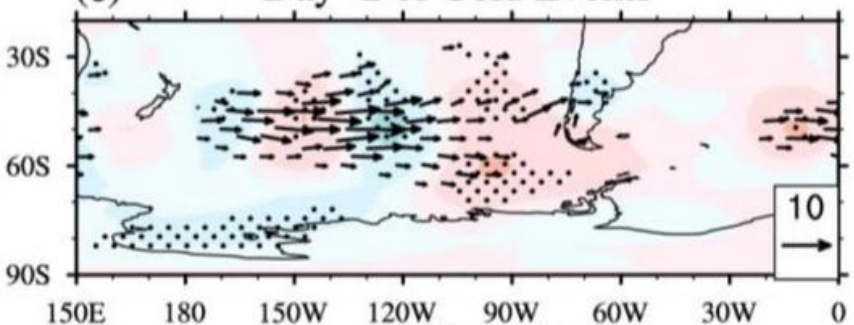

(f) Day -1 of Cold Events

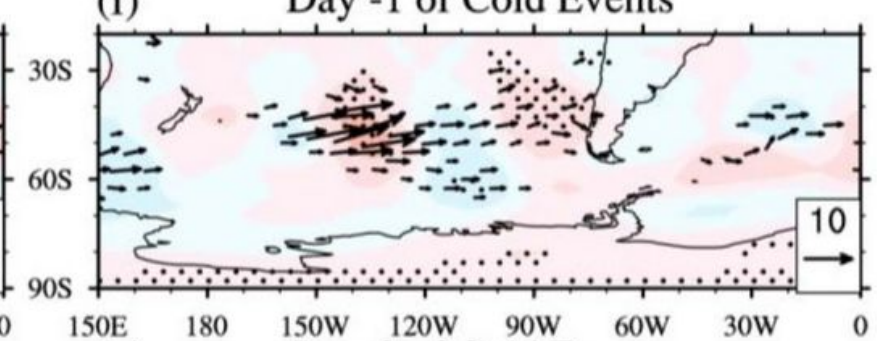

(g) Day 0 of Cold Events

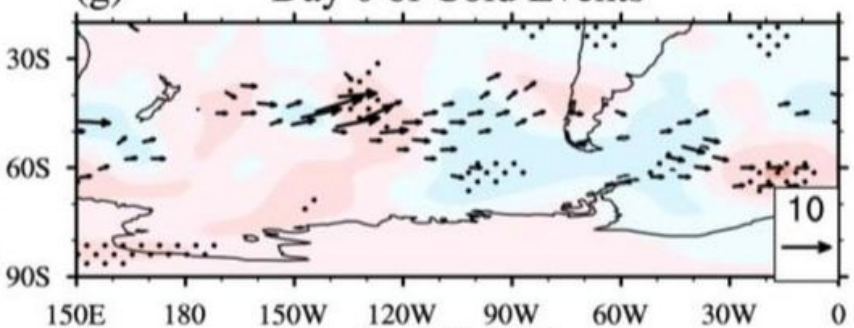

(h)

Day 1 of Cold Events

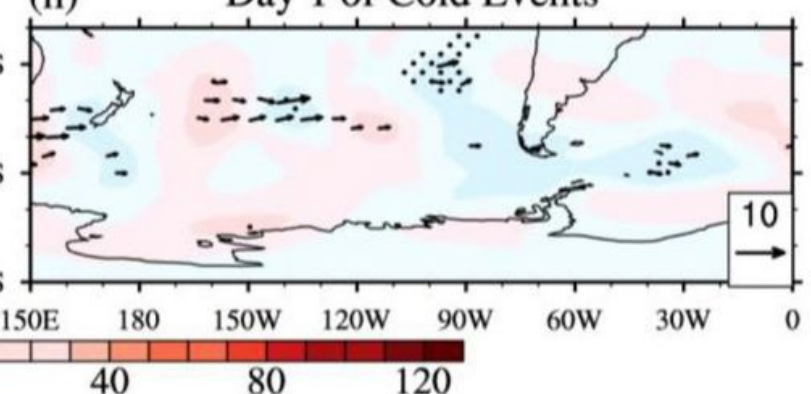

Figure 11

Composite anomalies of the synoptic component of geopotential height anomalies at $300 \mathrm{hPa}(\mathrm{m})$ (shading) and the attendant wave activity flux (vector) on days (a) -2, (b) -1, (c) 0 and (d) +1 of the warm events. (e)-(h) are the same as (a)-(d) but for the cold events. The dots indicate anomalies significant at the $95 \%$ confidence level. 

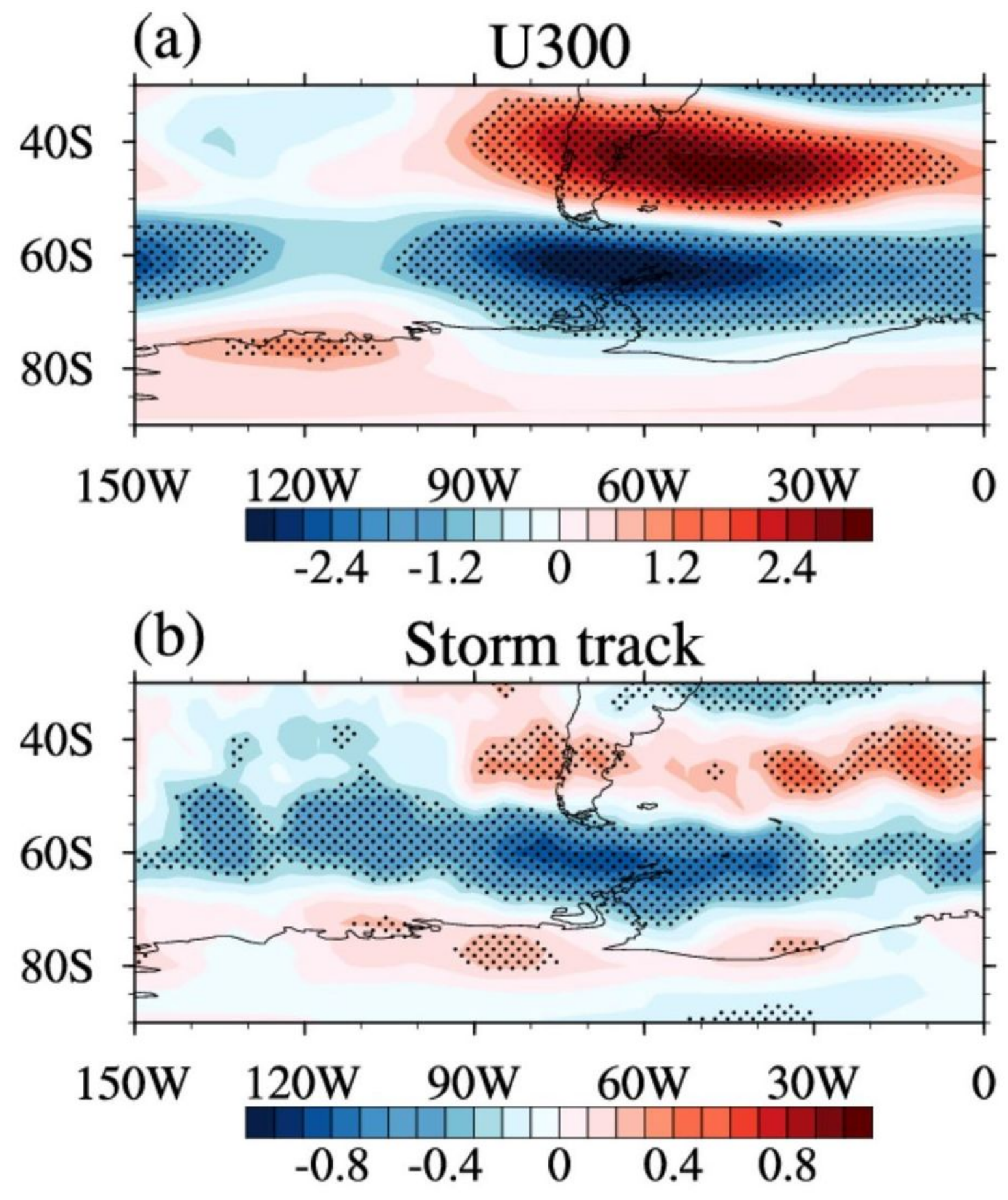

Figure 12

Composite anomalies of the seasonal component of (a) 300-hPa zonal wind (ms-1) and (b) 300-hPa storm track activity $(\mathrm{m})$ for the cold events. The dots indicate anomalies significant at the $95 \%$ confidence level. 


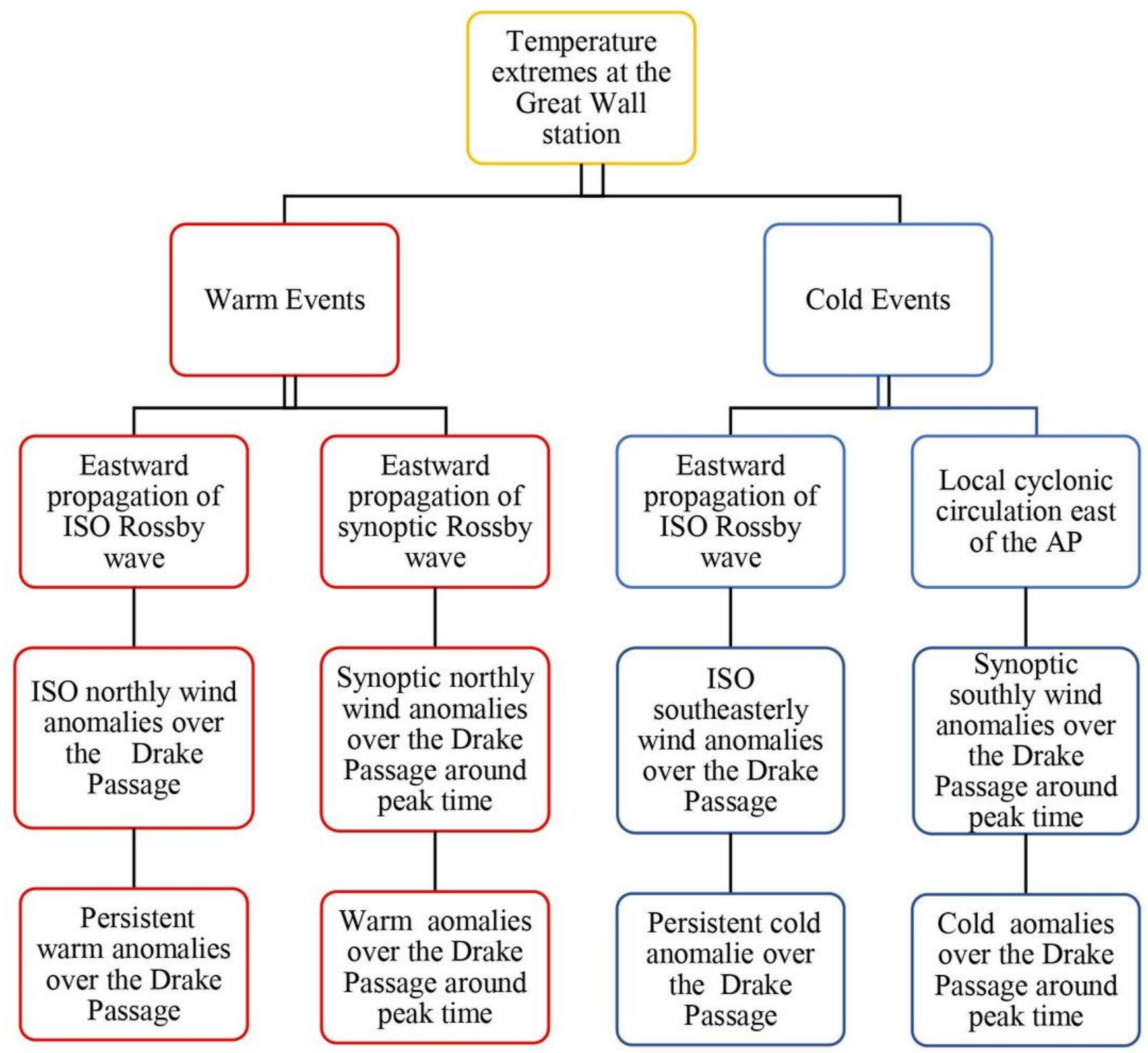

Figure 13

Schematic illustration of the role of atmospheric flow in the formation of summer temperature extremes at the Great Wall Station, Antarctic Peninsula, during austral summer. 